\title{
National Dementia Strategies: What Should Canada Learn?
}

Selina Chow, Ronald Chow, BMSc(C), Angela Wan, MD(C), Helen R. Lam, BSw(C), Kate Taylor, BA(C), Katija Bonin, MD(C), Leigha Rowbottom, MD(C), Henry Lam, MLS, Carlo DeAngelis, PharmD, Nathan Herrmann, MD

Division of Geriatric Psychiatry, Sunnybrook Health Sciences Centre, University of Toronto, Toronto, ON, Canada DOI:https://doi.org/10.5770/cgj.21.299

\section{ABSTRACT}

\section{Background}

In order to provide appropriate care for the aging population, many countries are adopting a National Dementia Strategy (NDS). On June 22, 2017, Canada announced it will become the 30th country to launch a NDS. In light of this announcement and as Canada prepares to develop its own NDS, we conducted this review to examine and compare the NDSs of the other previous 29 countries with Canadian government's policies to date.

\section{Methods}

NDSs were compared according to their major priorities. The primary endpoints were the framework conditions and key actions outlined in the strategies. Secondary endpoints included the years active, involvement of stakeholders, funding, and implementation.

\section{Results}

We were able to review and compare 25 of the 29 published NDSs. While the NDSs of each country varied, several major priorities were common among the strategies - increasing awareness of dementia, reducing its stigma, identifying support services, improving the quality of care, as well as improving training and education and promoting research.

\section{Conclusions}

This review comprehensively lists and compares the NDSs of different countries. The results should be of great interest to policy-makers, health-care professionals and other key stakeholders involved in developing Canada's forthcoming NDS. We hope that policy-makers in Canada can review other NDSs, learn from their example, and develop an effective NDS for our country.
Key words: dementia, national dementia strategy, government, policy

\section{INTRODUCTION}

In 2015, approximately 46.8 million people worldwide had dementia, and this figure will almost double every 20 years - 75 million in 2030 and 131.5 million by 2050 . With the medical advances and improved health care over the last century, the expected lifespan of individuals is increasing, accompanied by a rise in the number of people living with dementia. ${ }^{(1)}$

As a result of the increasing prevalence of dementia, the significant economic impact from this illness will only continue to grow. In 2015, the total estimated global cost of dementia was 818 billion USD, which accounted for 1.09\% of the world's GDP. However, these costs underestimate the true economic impact of dementia, as it is limited to caring for diagnosed patients, which is estimated to account for only one-quarter of all patients who suffer from dementia. ${ }^{(1)}$ As the awareness and knowledge of dementia increases in the near-future, more cases of dementia will likely be diagnosed; along with the projected increase in dementia among the aging population, health-care costs will only trend upwards.

In order to address this changing demographic, many countries are adopting a National Dementia Strategy (NDS) as a comprehensive government plan to provide appropriate medical care for people with dementia. A government dementia plan is a policy whereby the national government holds itself accountable to carry out its stated specific objectives and policy changes, although objectives can be accomplished with non-governmental collaborators. Recommendations on the process of public policy creation have been published, and are listed in Table 1. ${ }^{(2)}$ Created using input from various stakeholders (i.e., government agencies, legislators, residential and community care providers, professional and family carers, researchers, physicians, and people with dementia), the NDS is tailored specifically to the unique culture and demographics of each country to address a range of issues. Common priorities for NDSs include: raising awareness of 
TABLE 1.

Principles of population health policy ${ }^{\mathrm{a}}$

\begin{tabular}{ccl}
\hline Recommendation & \\
\hline 1 & Principle & Include directives, plans, and courses of action documented in writing \\
2 & - & Prioritize early detection, treatment, and rehabilitation following disease among at-risk and symptomatic individuals \\
3 & - & Include political, economic, epidemiological, ethical, behavioral, and legal considerations when developing population \\
4 & - & Pealth policy \\
5 & Population health needs vary among groups across different demographics and jurisdictions \\
6 & - & Population health policies need to balance standardization with customization of interventions \\
& into account & To manage population health, align strategic planning with the management of human resources \\
& Identify population health needs through available health needs assessments and input from affected population members
\end{tabular}

adapted from Reference \#2.

the disease, combating stigma, identifying support services, quantifying the number of individuals with dementia, assessing and improving the quality of dementia care, and assessing the availability and access to diagnostic services. These strategies have been well-received and reported as the single most powerful tool to transform dementia care and support within a country. ${ }^{(3,4)}$

On June 22, 2017, Canada announced it will become the 30 th country to launch a National Dementia Strategy. ${ }^{(4)}$ The timing of this announcement was curious in view of the fact that, at the G8 Dementia Summit in London on December 11, 2013, the G8 Health Ministers met to discuss how to shape an effective international response to dementia. They committed to carry out 12 dementia public health policy actions, with Canada and France co-leading this initiative. ${ }^{(5)}$ Subsequent to this, on September 11, 2014, at a meeting with leading researchers and dementia industry experts in Ottawa, the Federal Health Minister acknowledged that Canada was the only G7 nation without a NDS. As such, the government began planning a new National Dementia Research and Prevention Plan. ${ }^{(6)}$ Canada's laggard response to NDS development can only be a matter of speculation.

In light of the recent news that Canada is now finally developing a NDS, we conducted this review with the purpose of examining and comparing the NDSs across the 29 prior countries with Canadian government policies to date. This information could provide valuable insight for clinicians, researchers, and policy-makers about pre-existing policies in other countries, to potentially aid in the development of a comprehensive and effective strategy for Canada.

\section{METHODS}

\section{Selection Criteria}

All the NDSs were retrieved from Alzheimer's Disease International. ${ }^{(3)}$ For countries that have published several
NDSs over time, only the current or most recent strategy was included, to allow for cross-country comparison. For strategies published in foreign languages, online translation services were employed. Strategies that were not publicly available from its corresponding country were excluded.

\section{Data Extraction and Endpoints}

The 29 countries are defined according to Alzheimer's Disease International. ${ }^{(3)}$ NDSs of countries were compared according to their major priorities. The primary endpoints were the framework conditions and key actions outlined in the strategy. Secondary endpoints included the years active, involvement of stakeholders, funding, and implementation.

Data extraction from the 29 national strategies was delegated among the authors, who worked in pairs. For each national strategy, one author extracted endpoints and another author verified the extracted data to ensure accuracy and consistency in the results.

\section{RESULTS}

Of the 29 countries identified as having a NDS, 25 were published in English or in a language/medium that could be readily translated to English using online translation services. (7-36) The literature published by the countries of Argentina, (37) Costa Rica, (38) Macau, and Slovenia( ${ }^{(39)}$ were not publicly available online and/or could not be translated to English for inclusion in our review.

A summary of each NDS is provided in Table 2. While the NDSs of each country varied, several major priorities were common among most of the strategies: increasing awareness of dementia, reducing the stigma surrounding the illness, identifying support services, improving the quality of care, as well as improving training and education and promoting research. Several NDSs also specified the funding received to carry out the strategy, along with how the strategy will be implemented. 
CHOW: NATIONAL DEMENTIA STRATEGIES

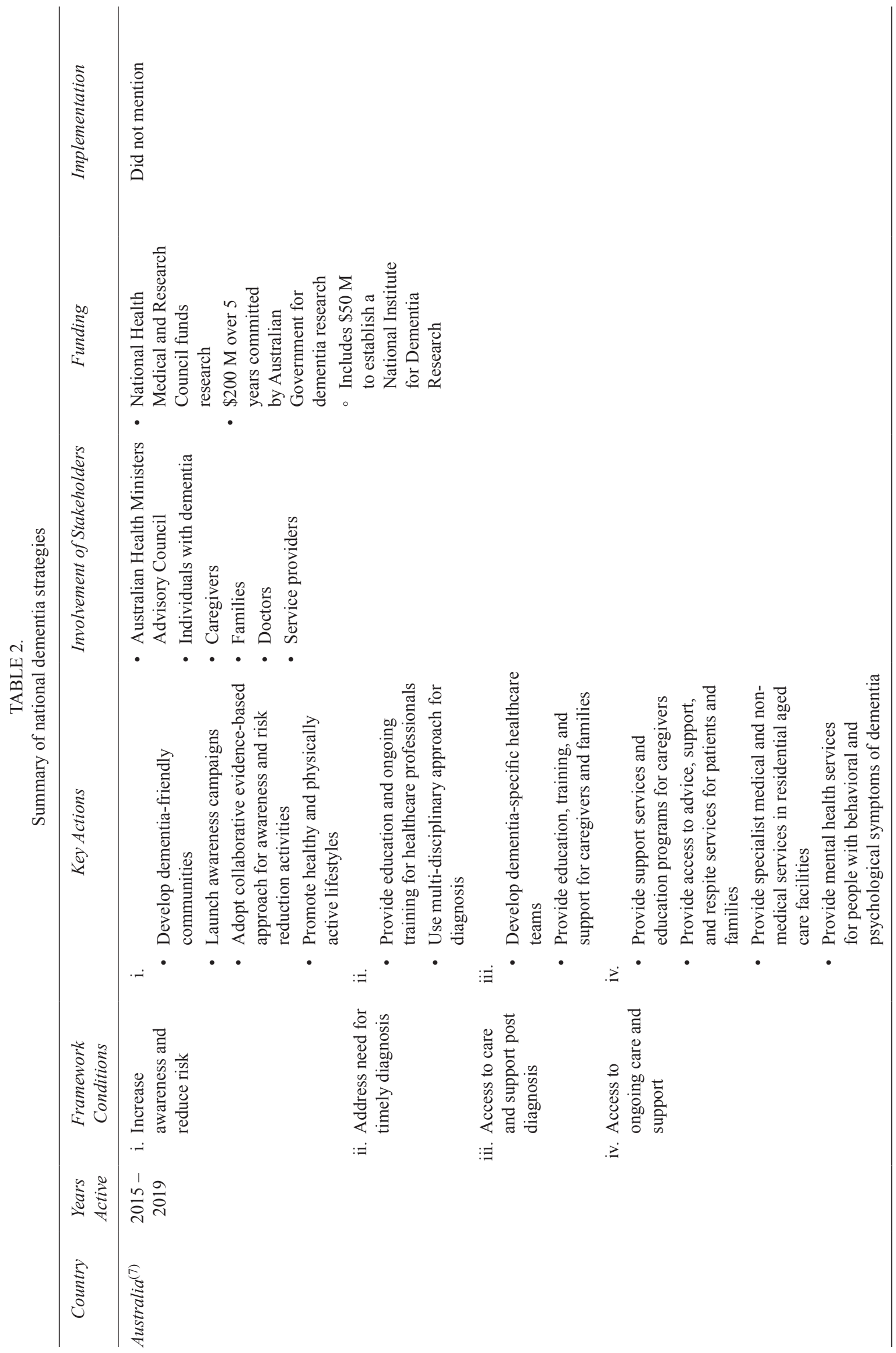


CHOW: NATIONAL DEMENTIA STRATEGIES

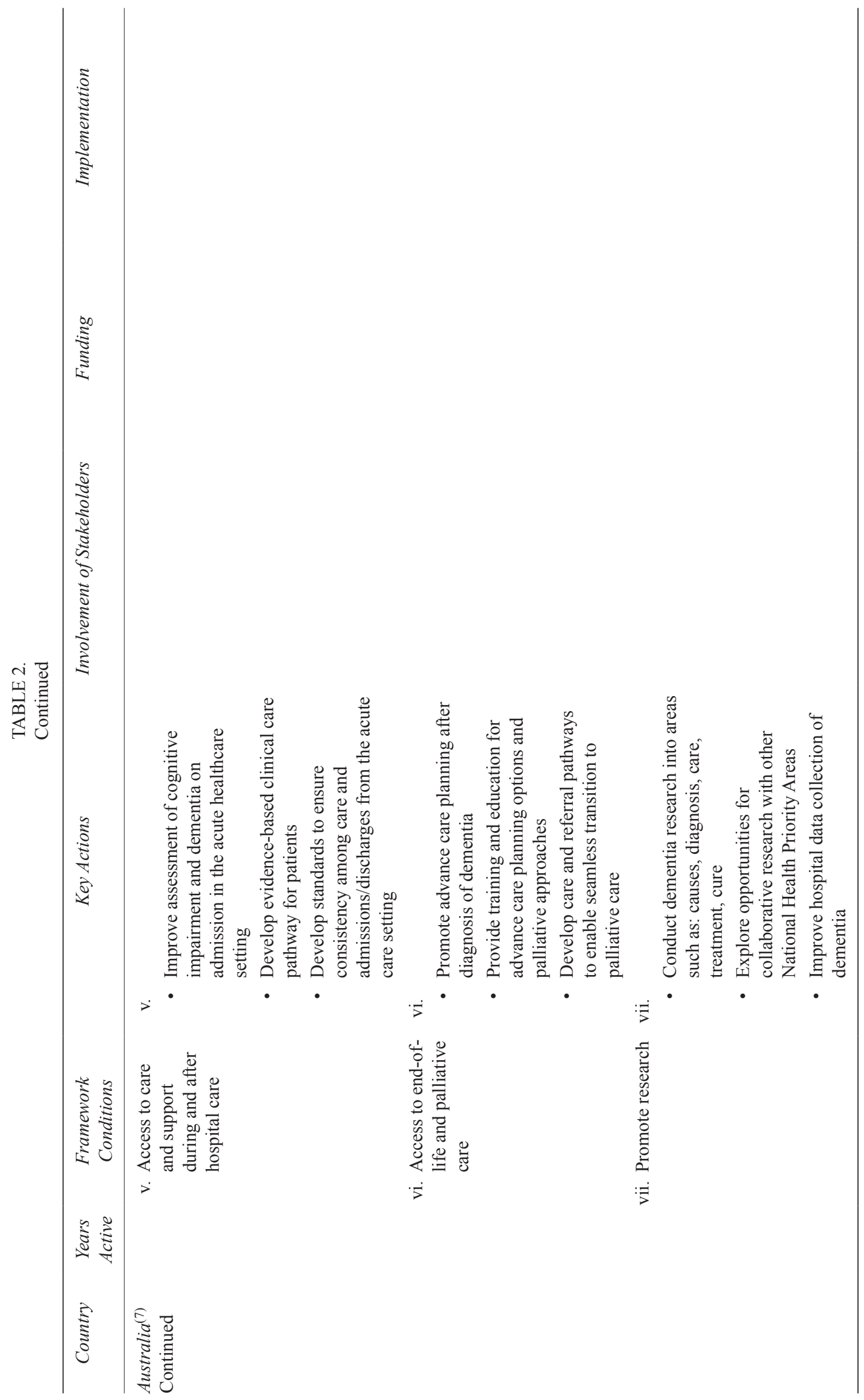


CHOW: NATIONAL DEMENTIA STRATEGIES

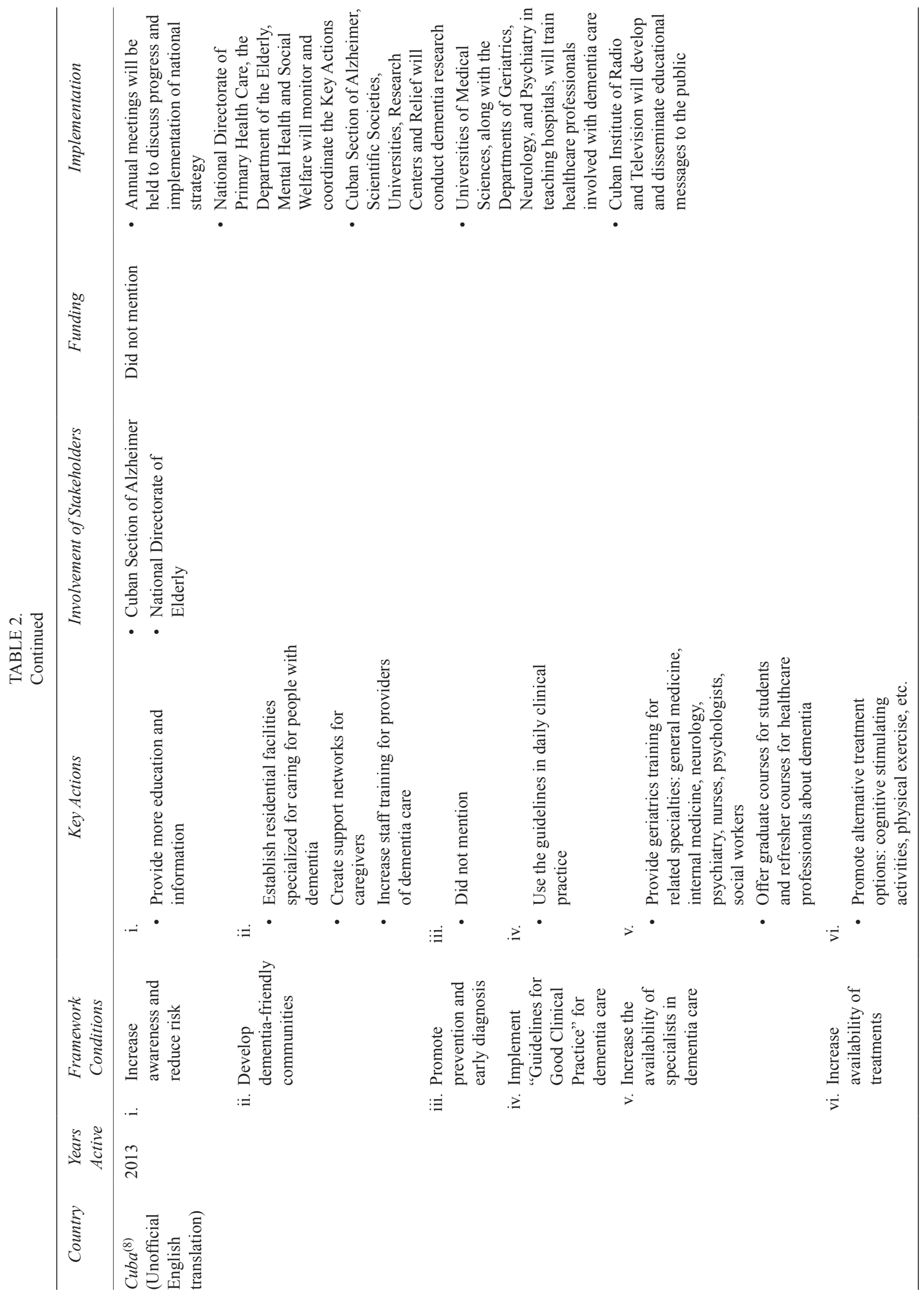


CHOW: NATIONAL DEMENTIA STRATEGIES

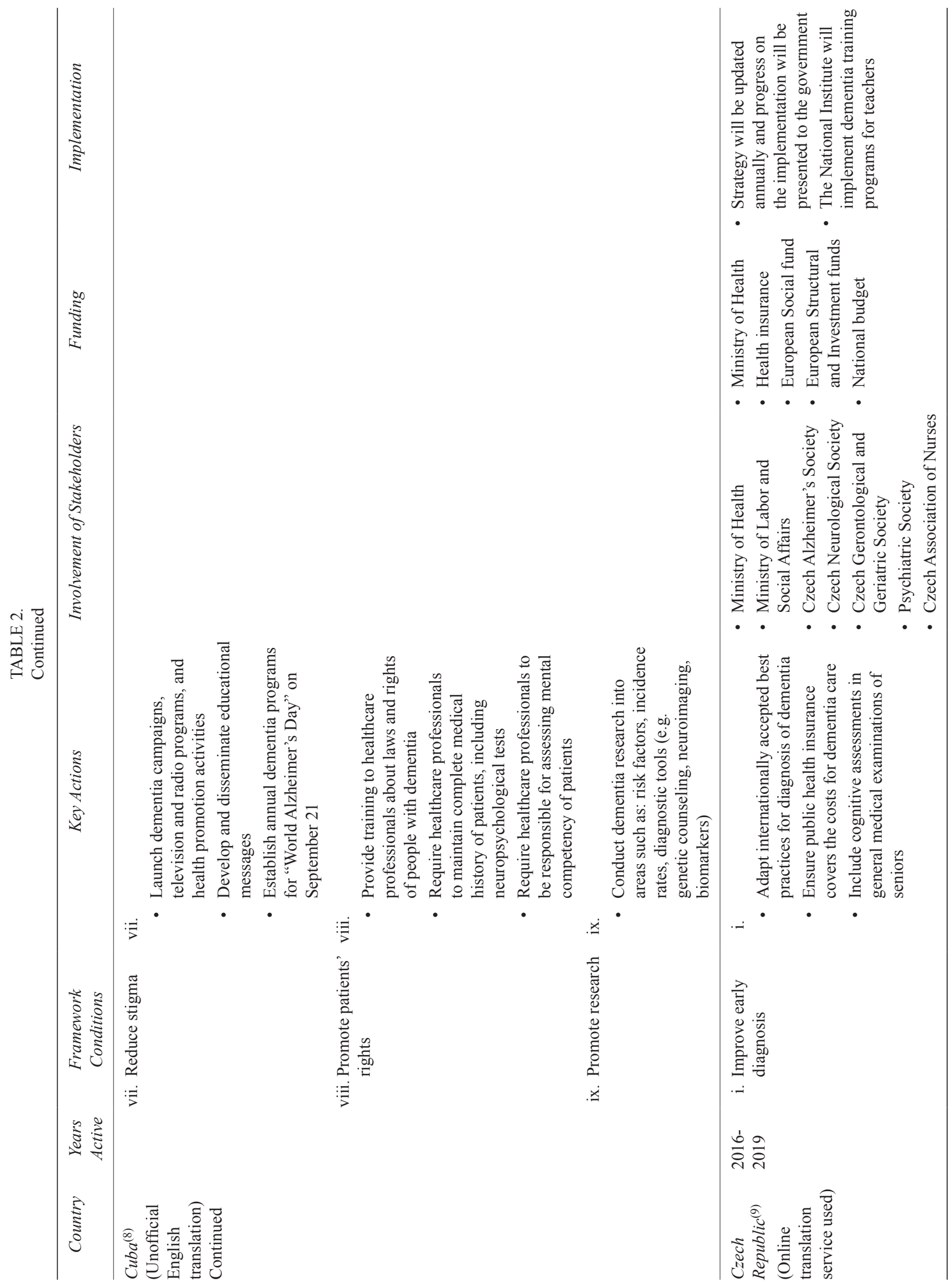


CHOW: NATIONAL DEMENTIA STRATEGIES

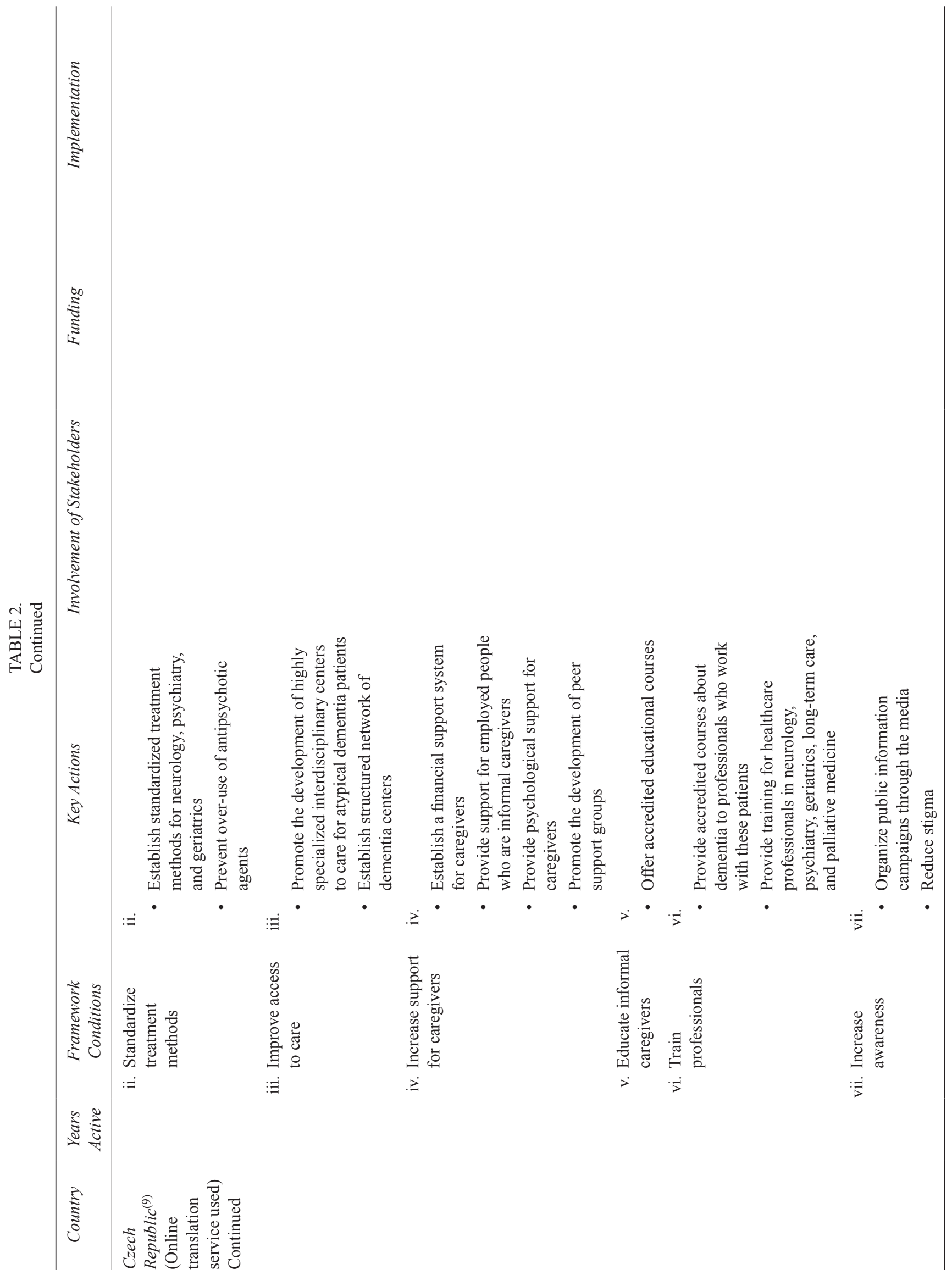


CHOW: NATIONAL DEMENTIA STRATEGIES

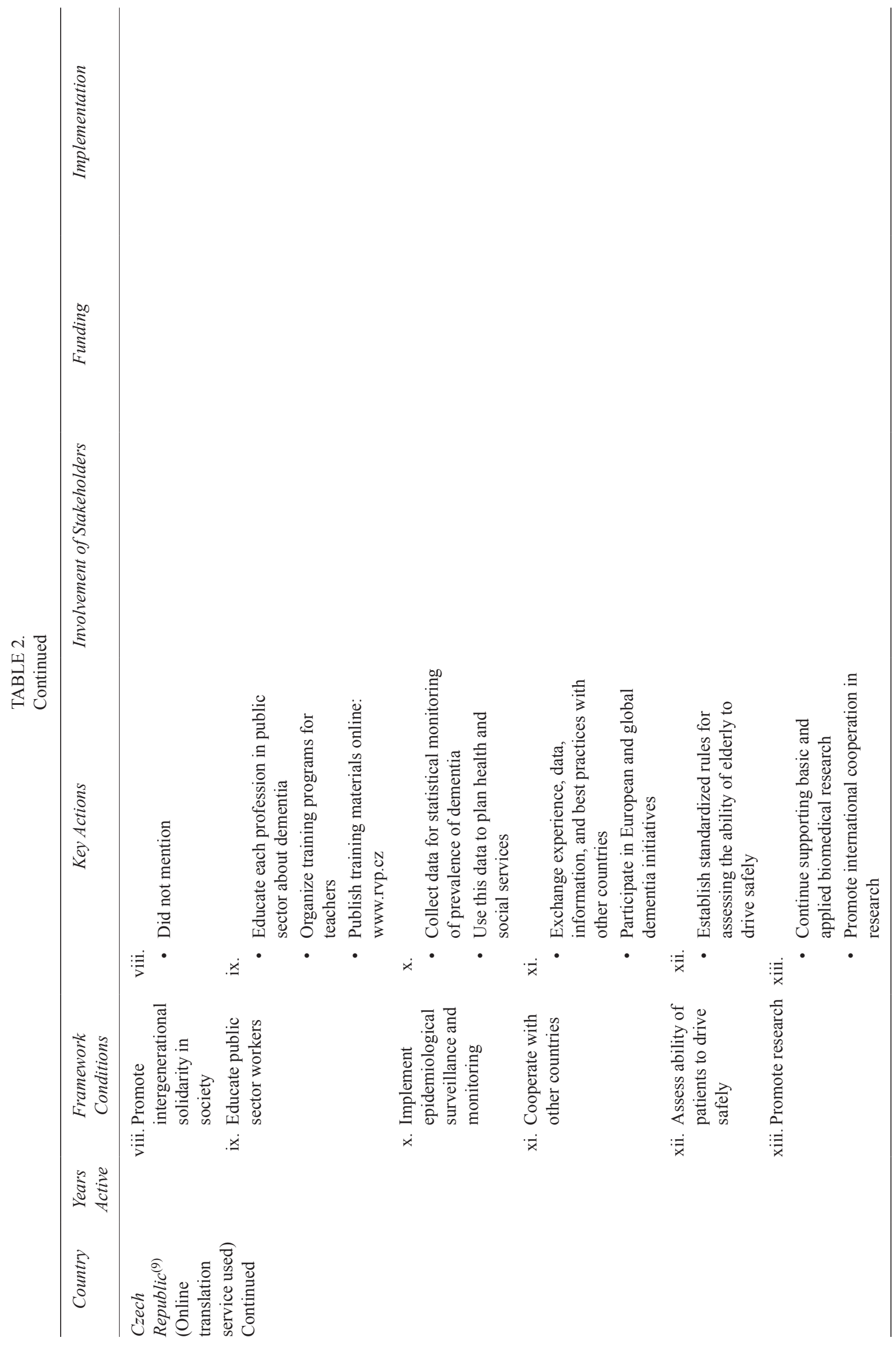




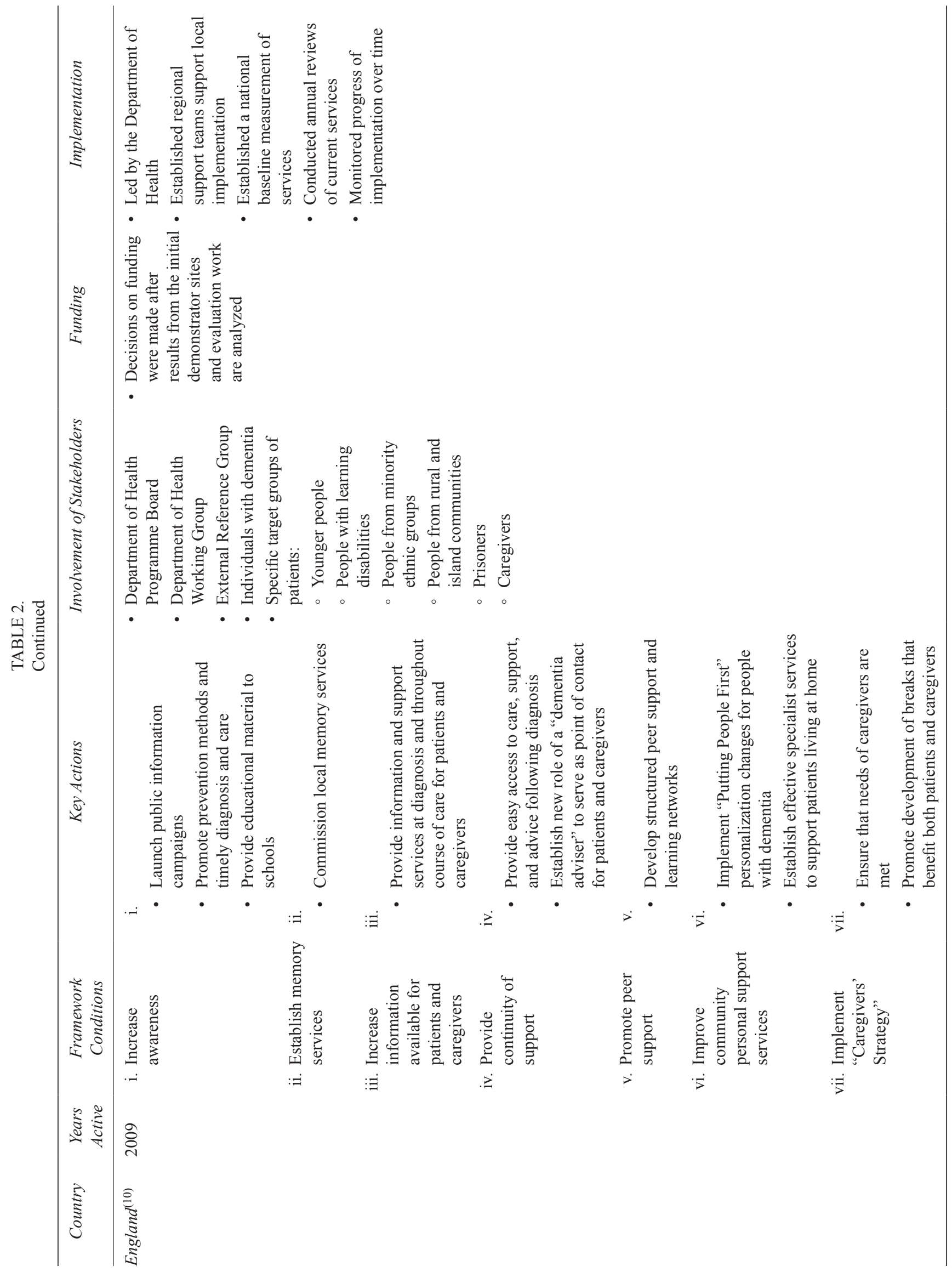


CHOW: NATIONAL DEMENTIA STRATEGIES

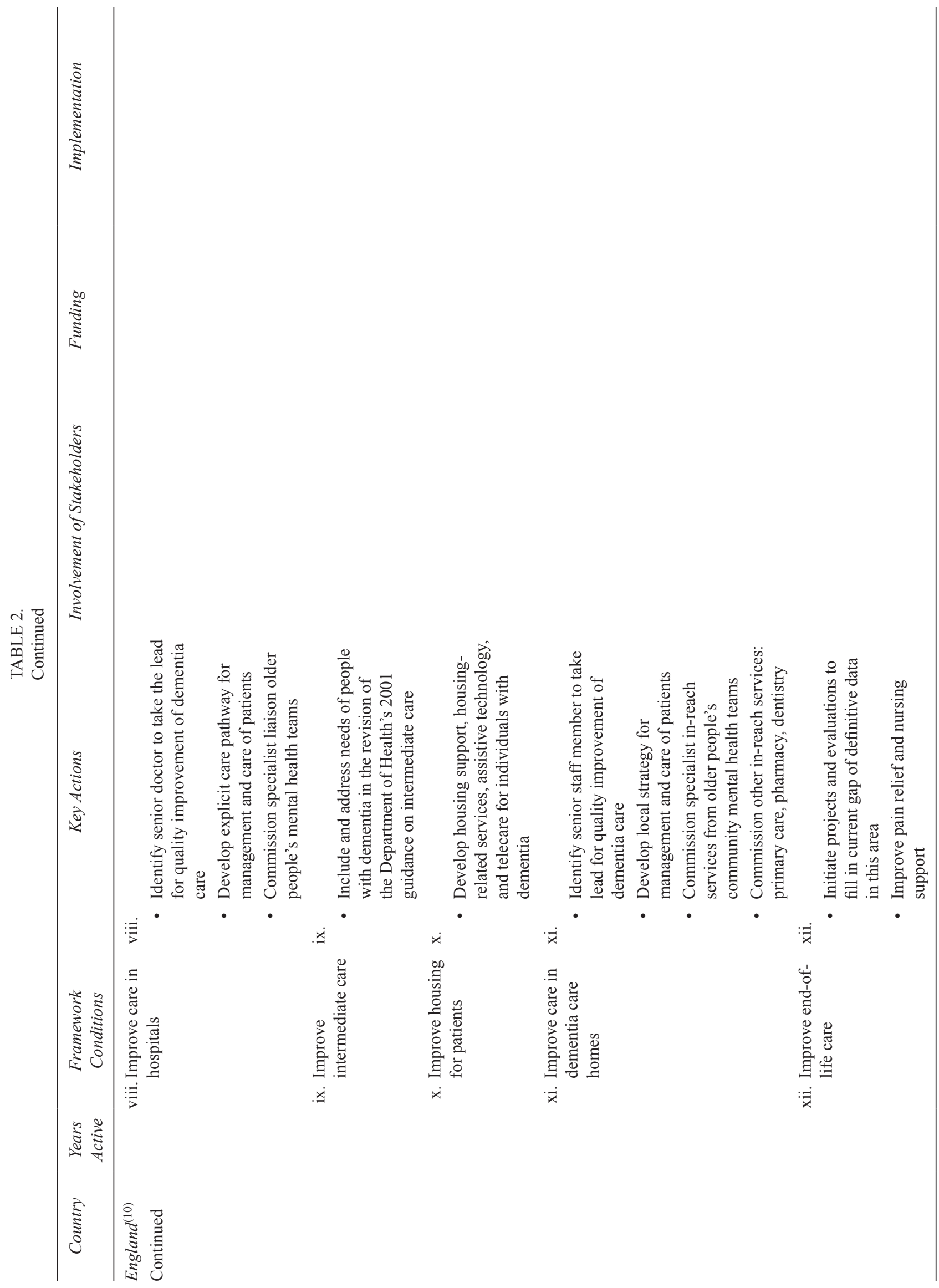


CHOW: NATIONAL DEMENTIA STRATEGIES

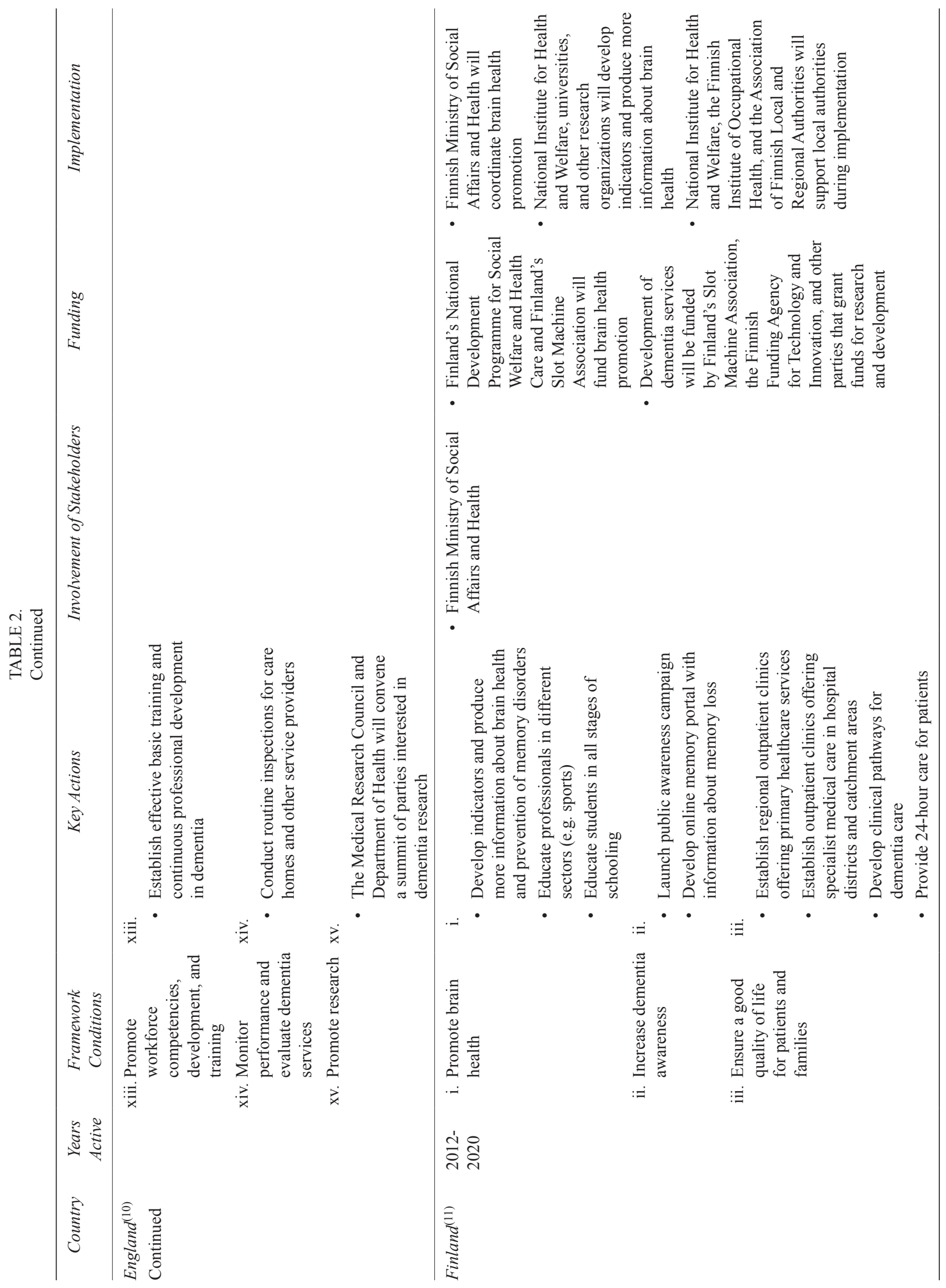


CHOW: NATIONAL DEMENTIA STRATEGIES

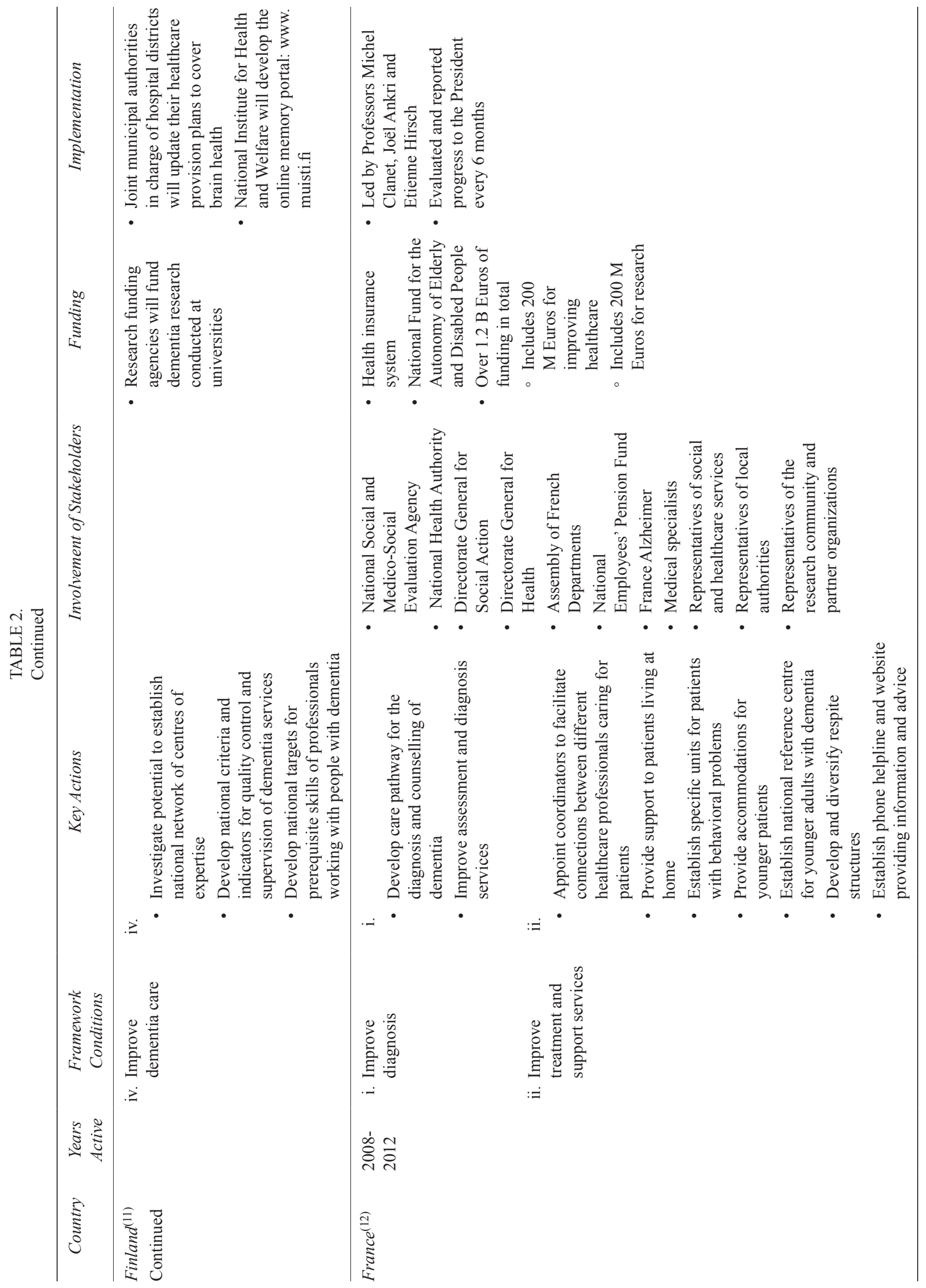




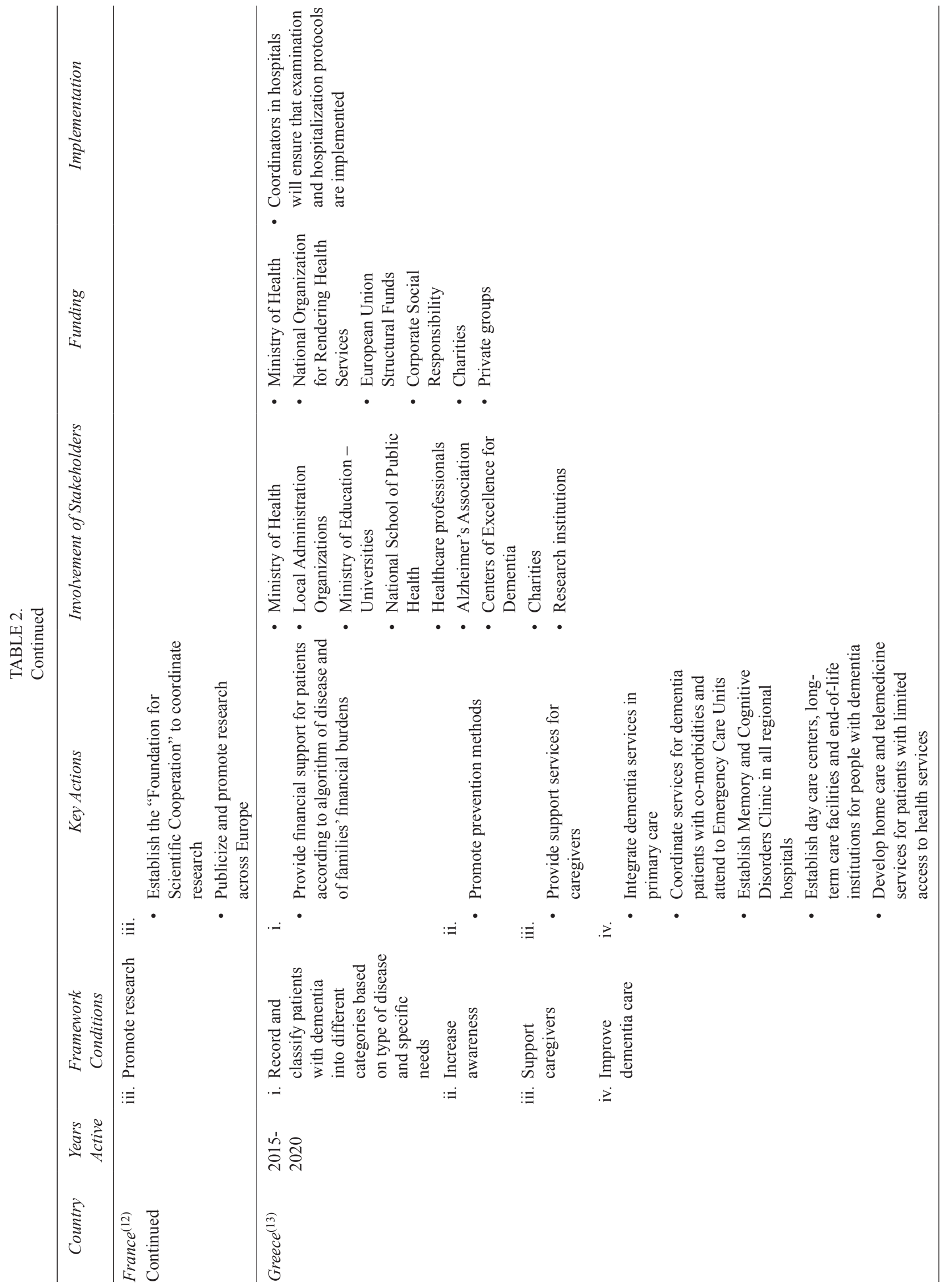


CHOW: NATIONAL DEMENTIA STRATEGIES

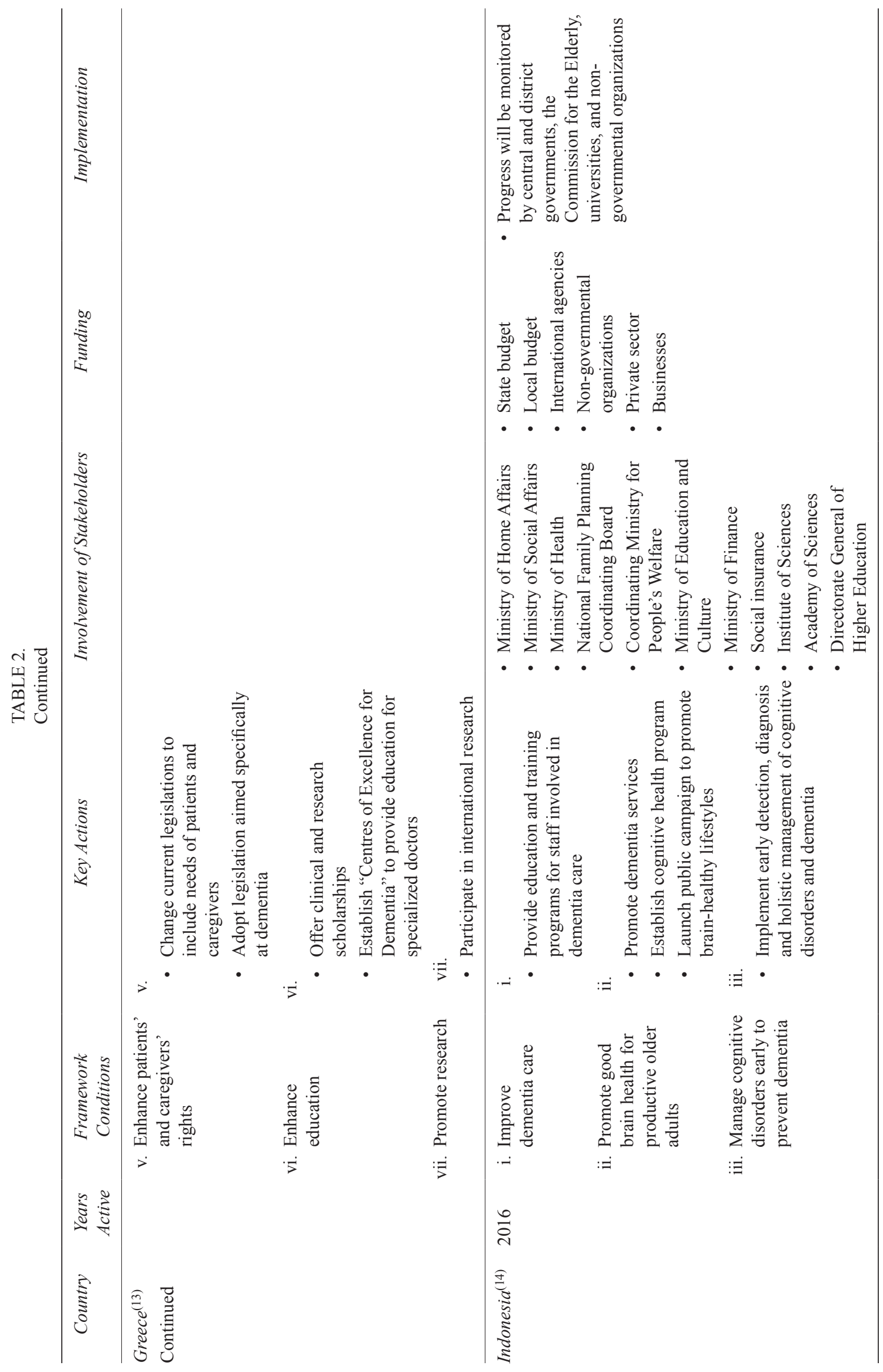




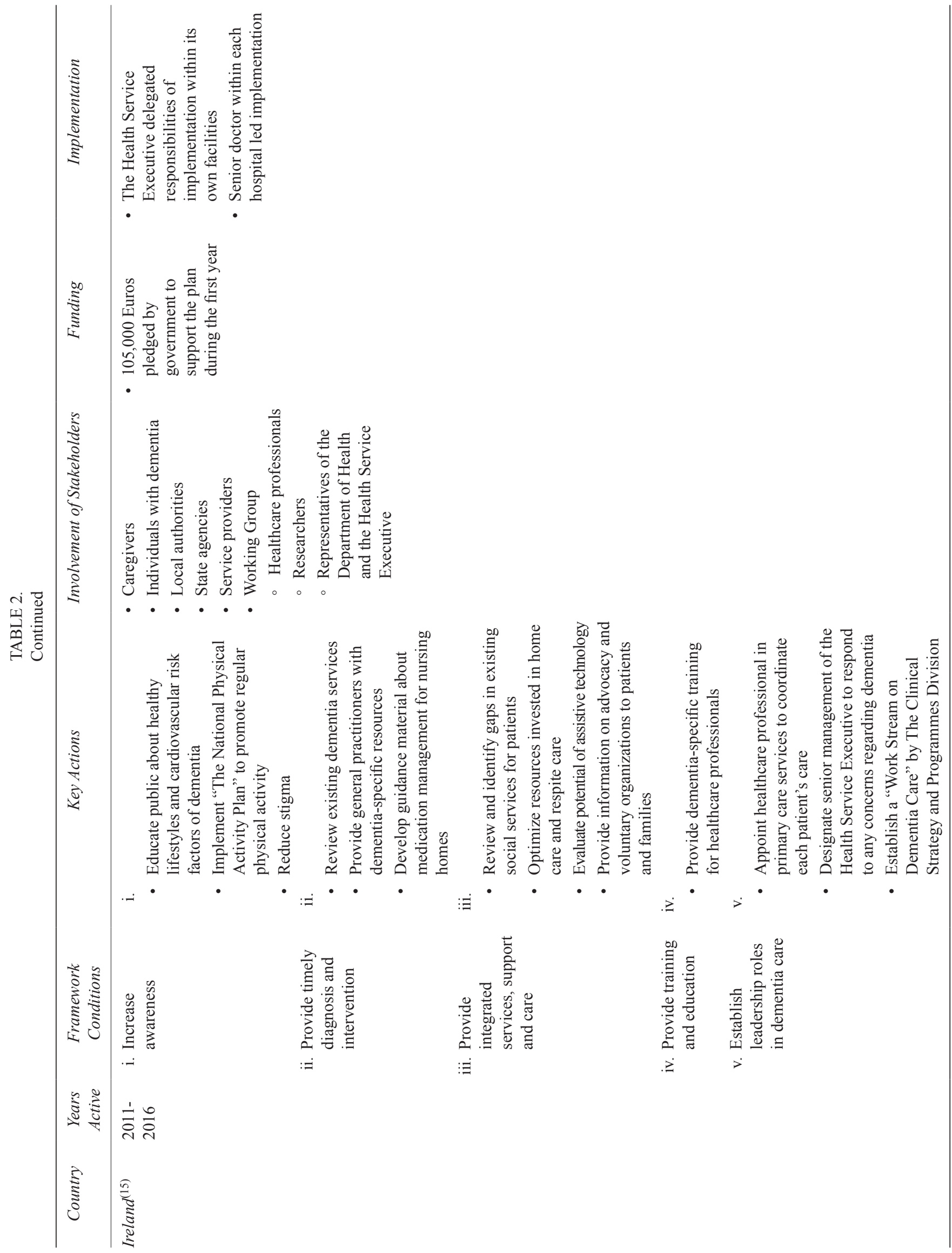




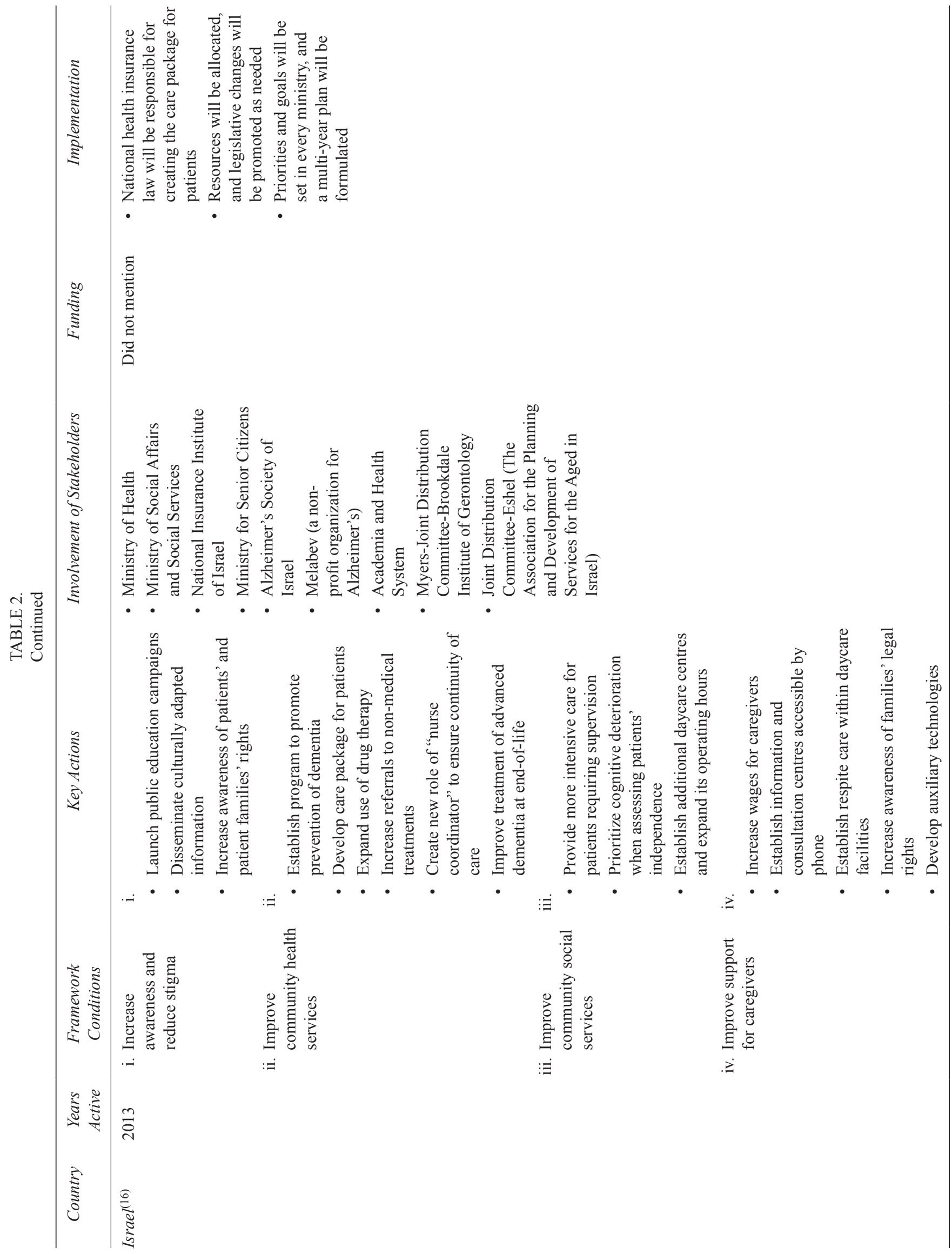


CHOW: NATIONAL DEMENTIA STRATEGIES

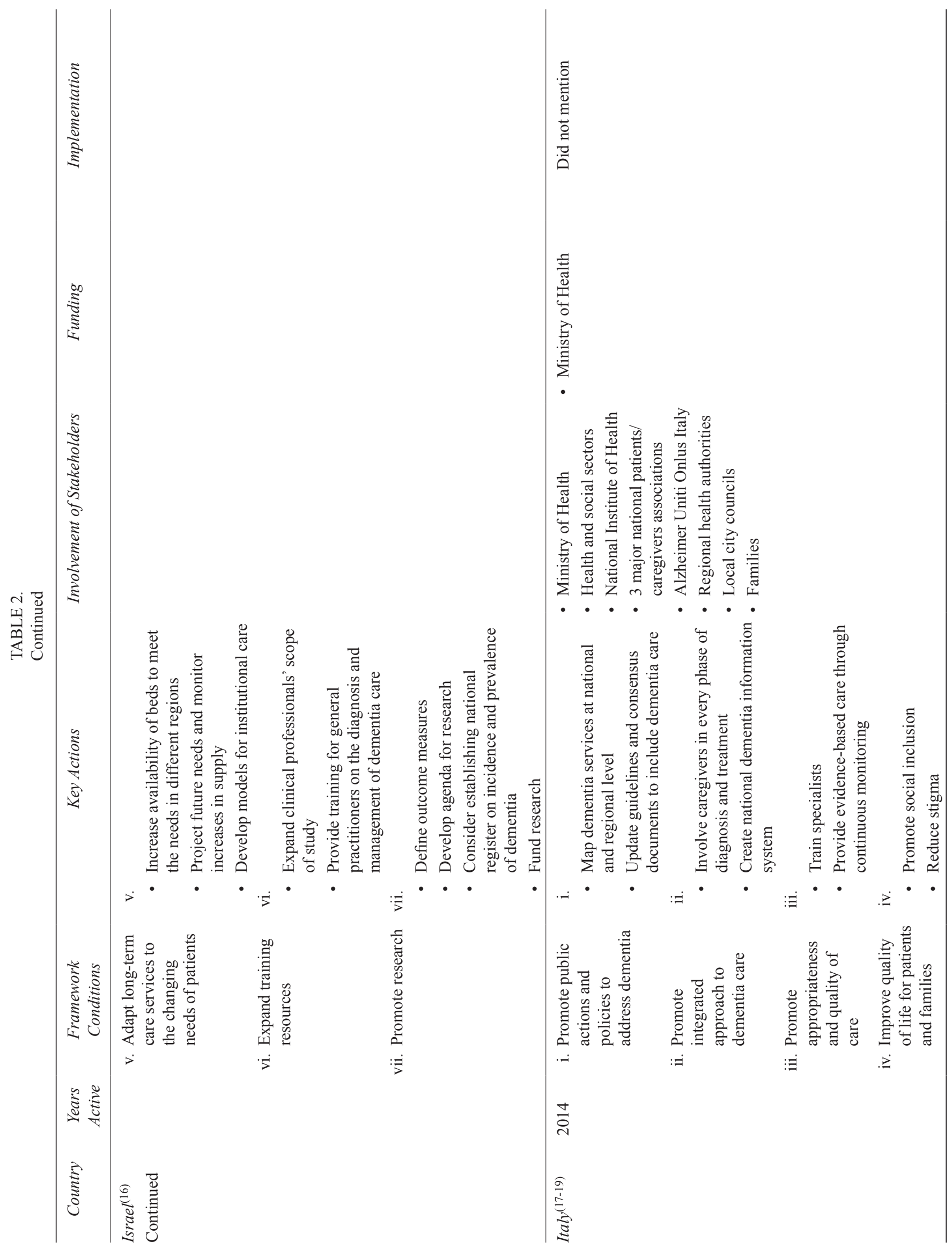


CHOW: NATIONAL DEMENTIA STRATEGIES
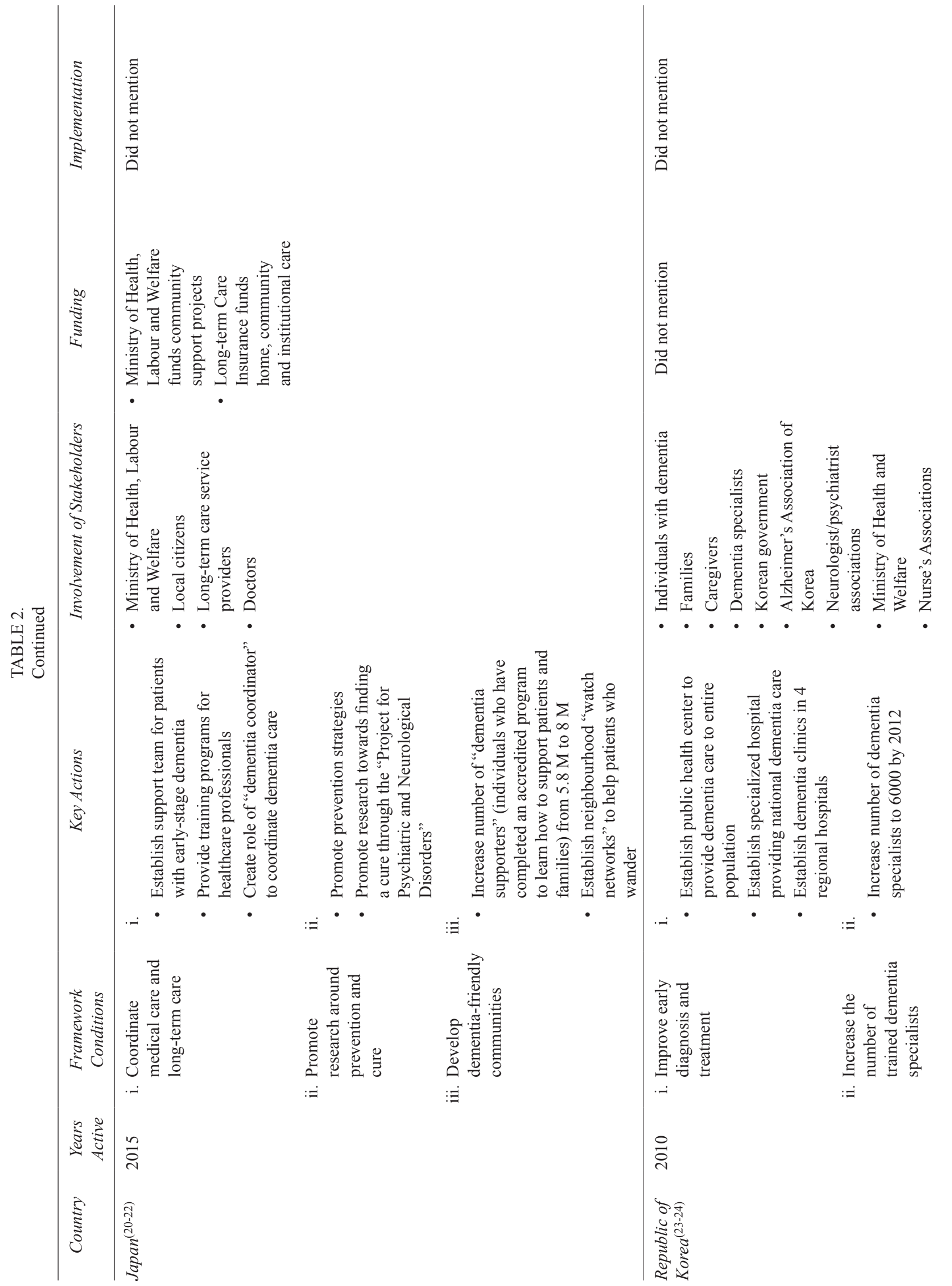
CHOW: NATIONAL DEMENTIA STRATEGIES

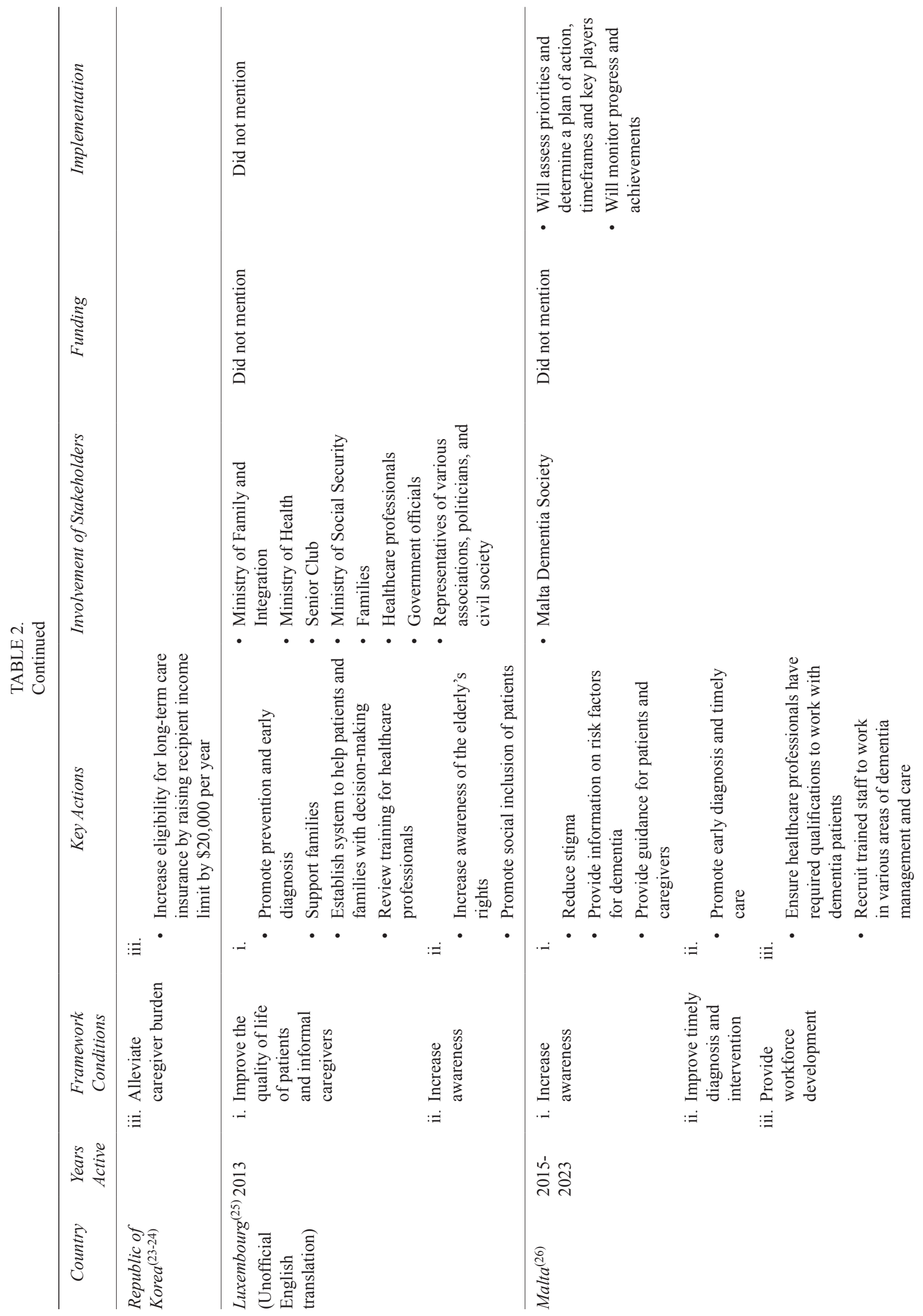


CHOW: NATIONAL DEMENTIA STRATEGIES

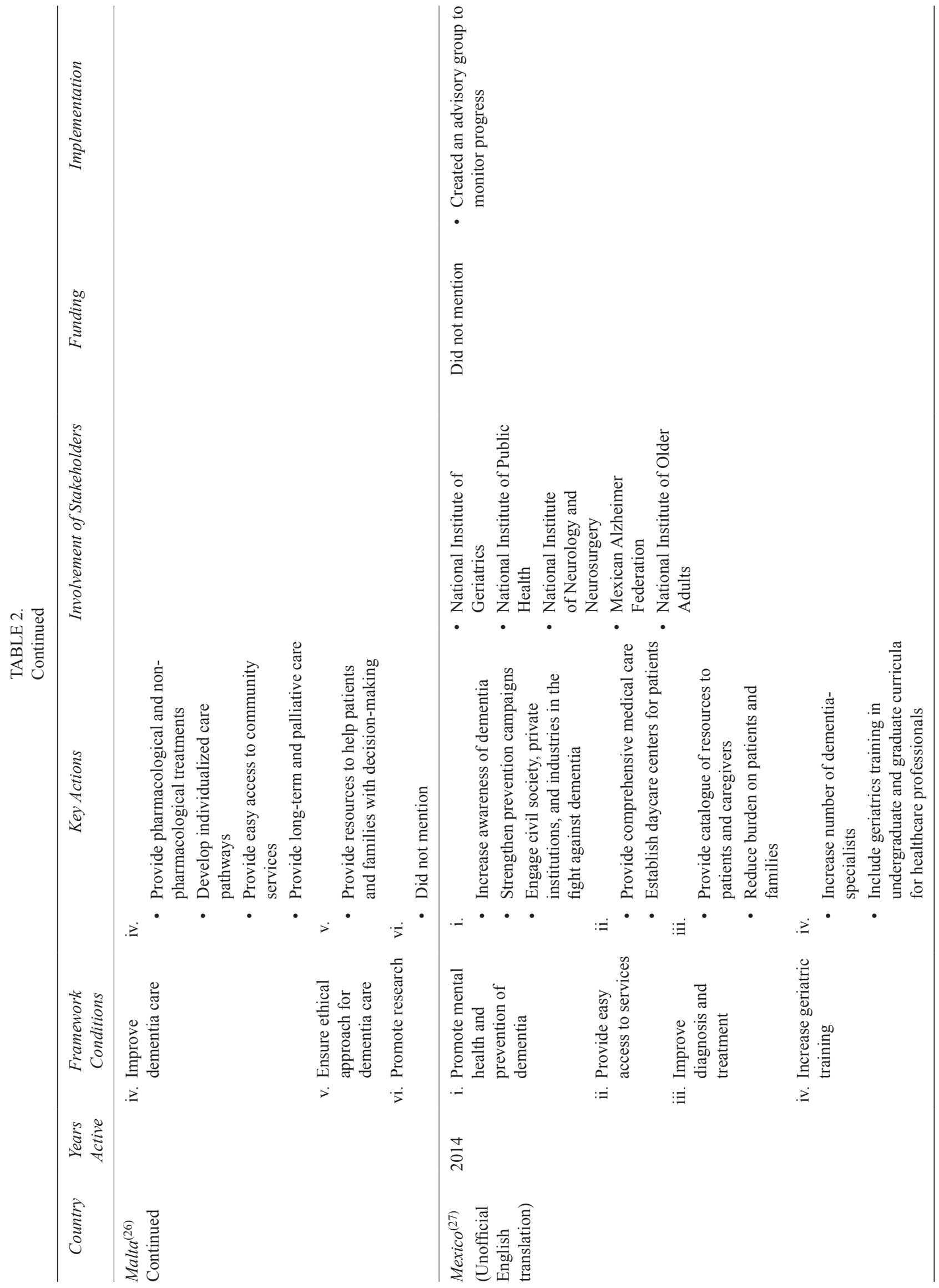


CHOW: NATIONAL DEMENTIA STRATEGIES
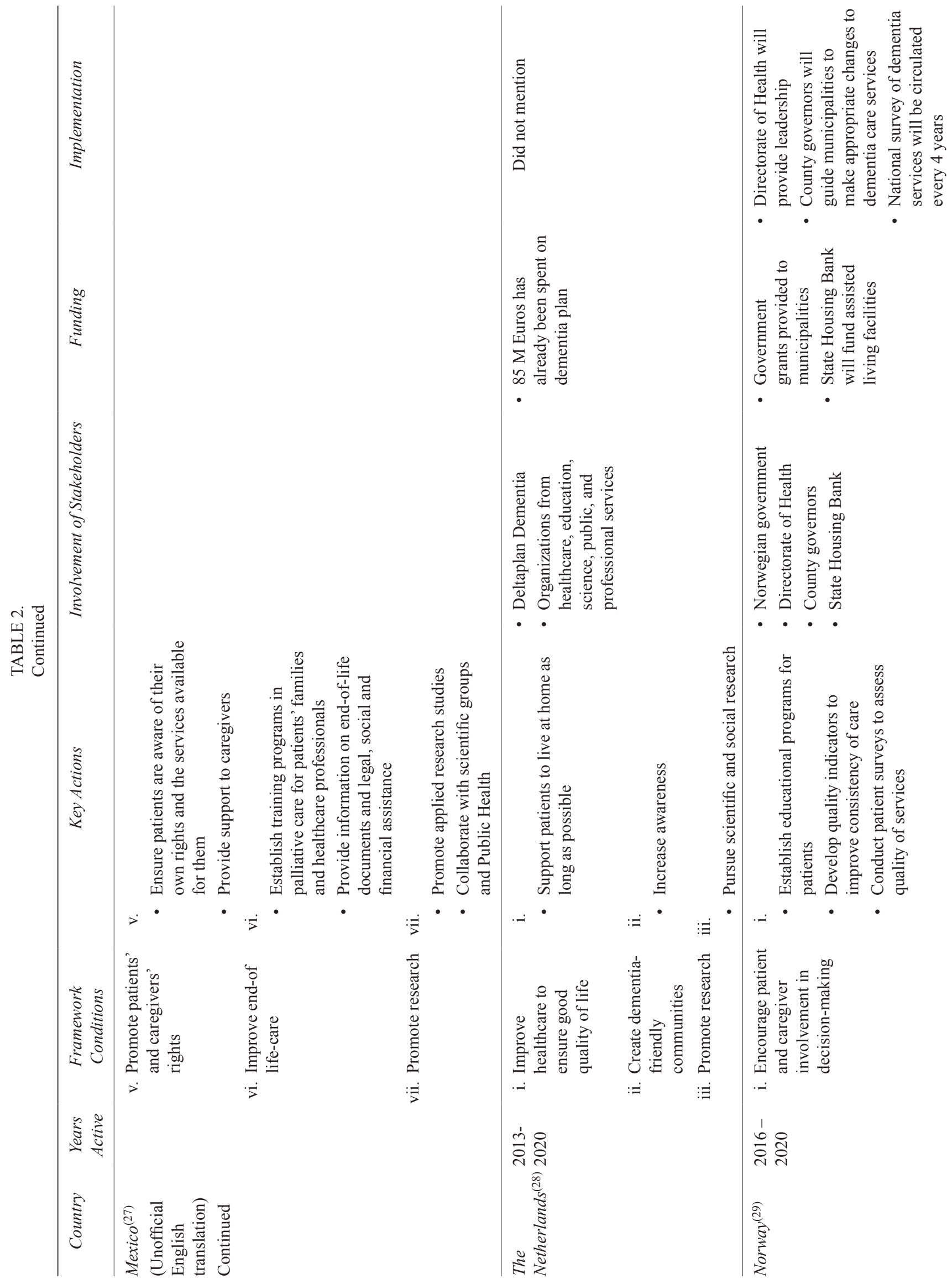
CHOW: NATIONAL DEMENTIA STRATEGIES

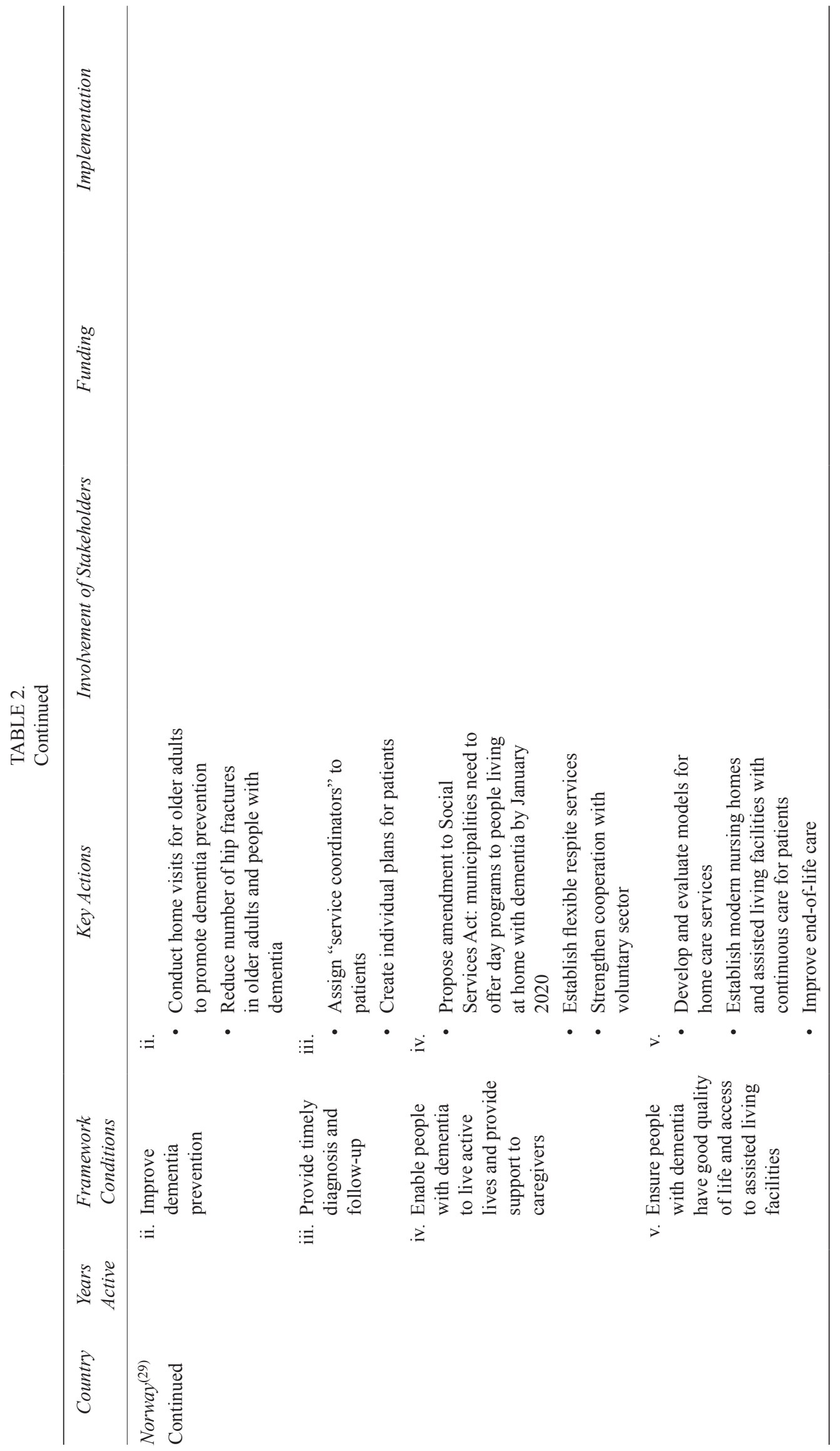


CHOW: NATIONAL DEMENTIA STRATEGIES

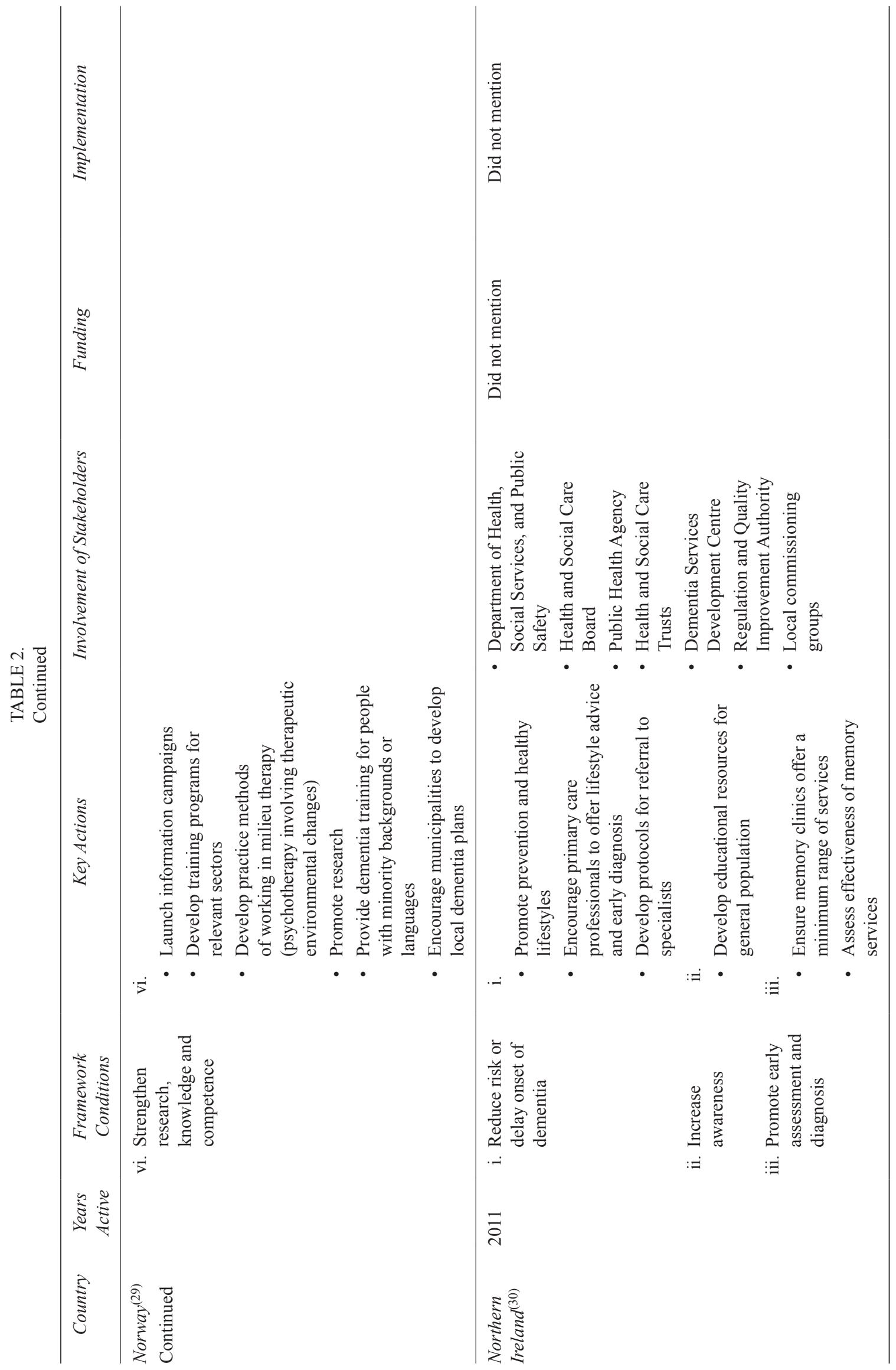


CHOW: NATIONAL DEMENTIA STRATEGIES

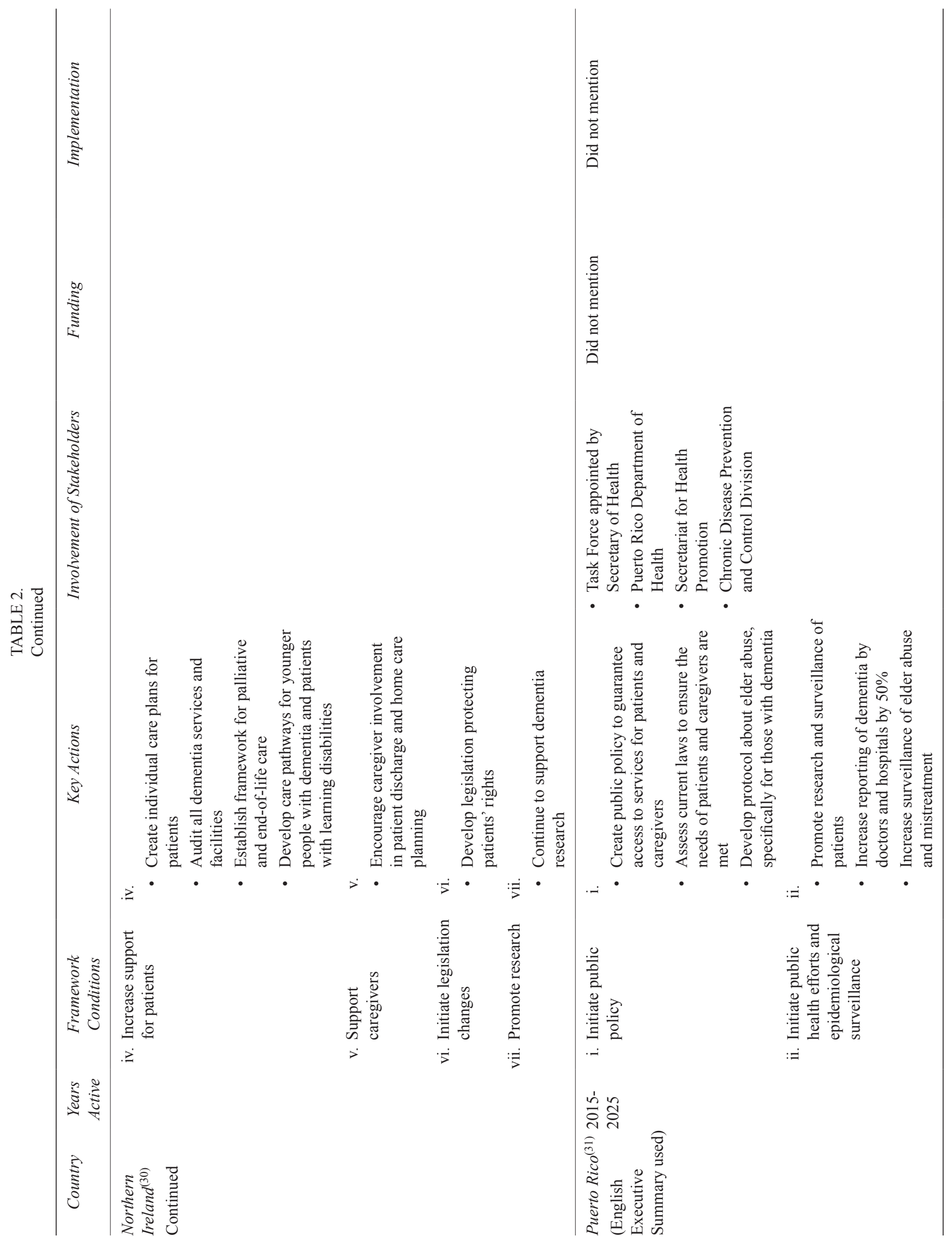


CHOW: NATIONAL DEMENTIA STRATEGIES

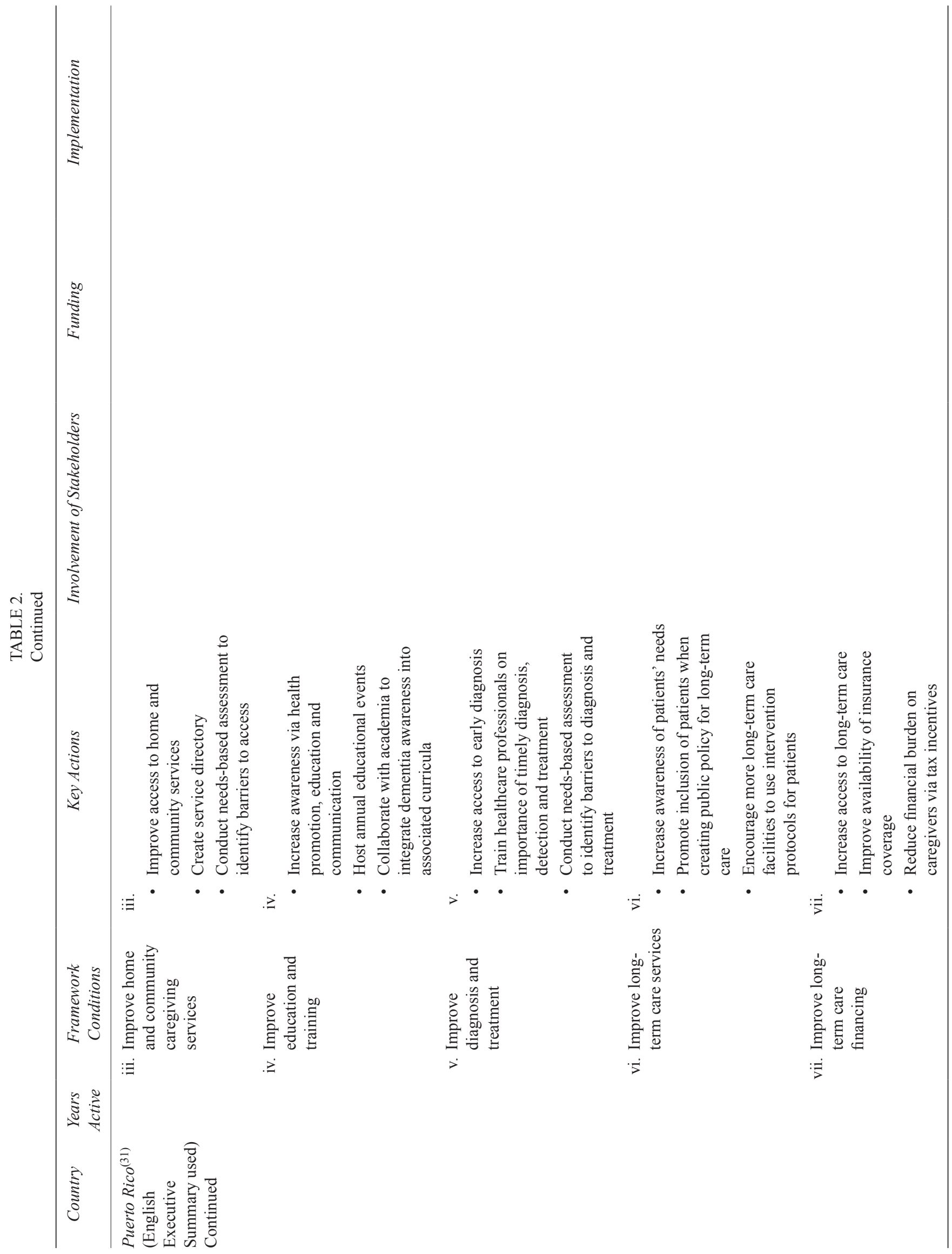


CHOW: NATIONAL DEMENTIA STRATEGIES

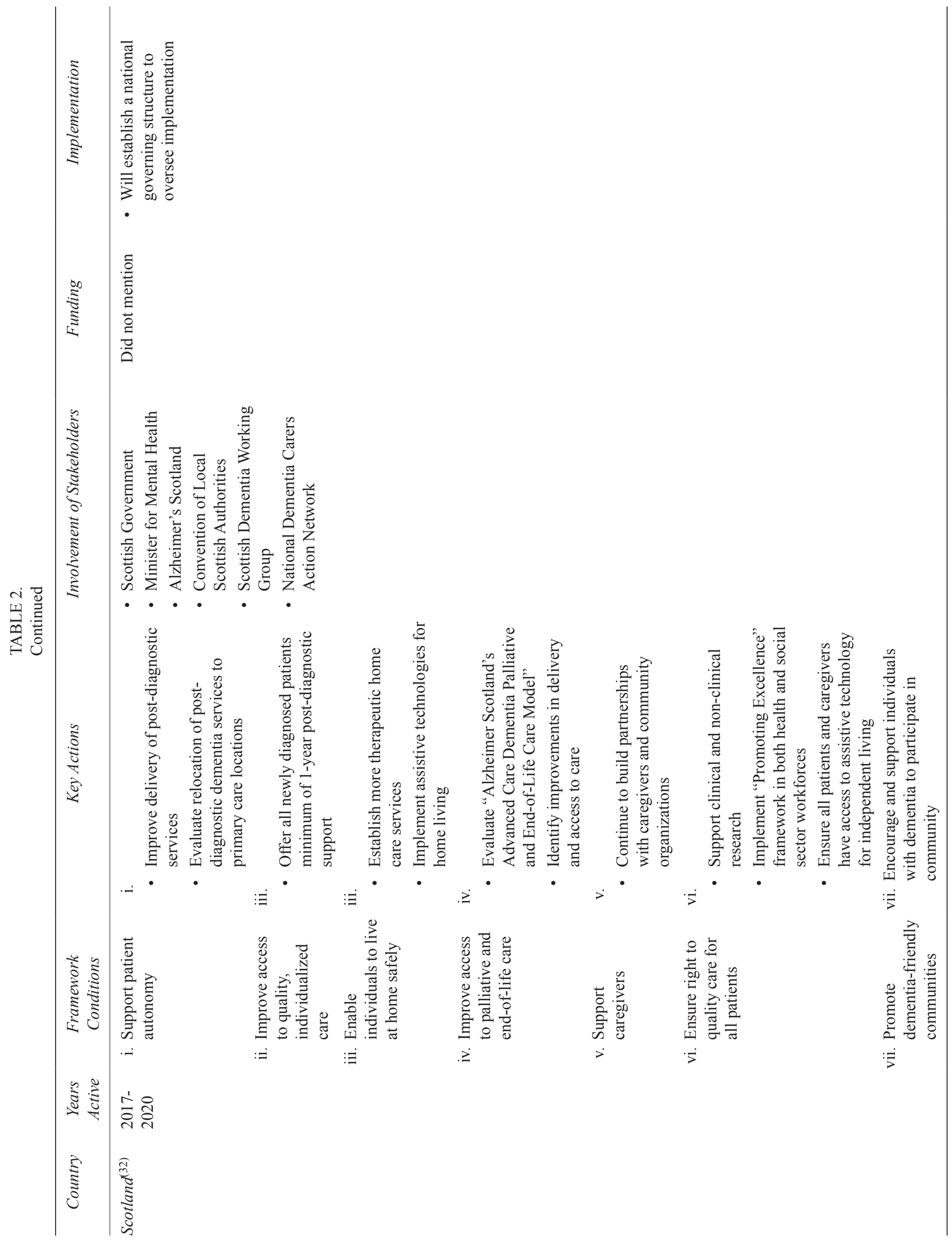


CHOW: NATIONAL DEMENTIA STRATEGIES

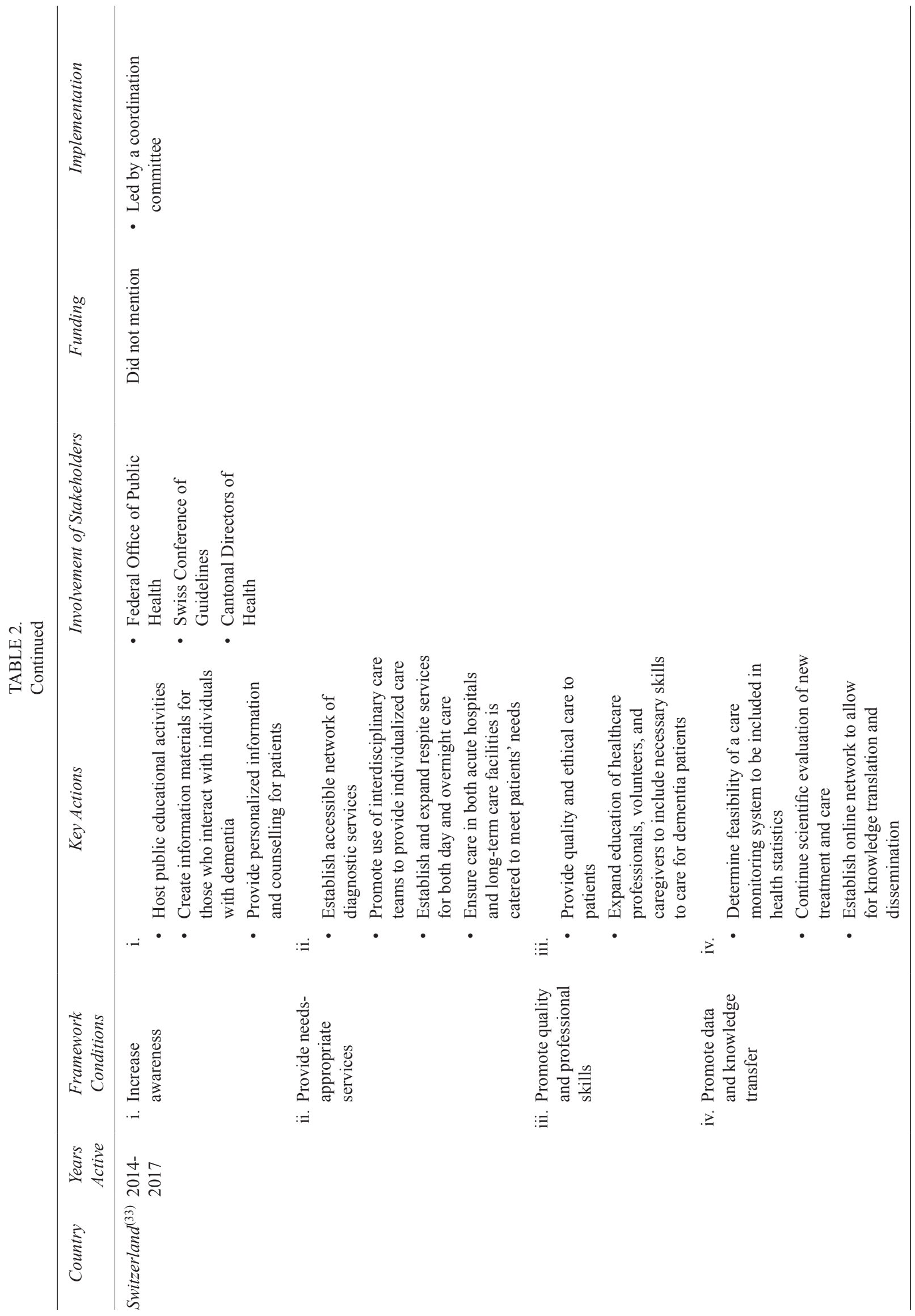


CHOW: NATIONAL DEMENTIA STRATEGIES

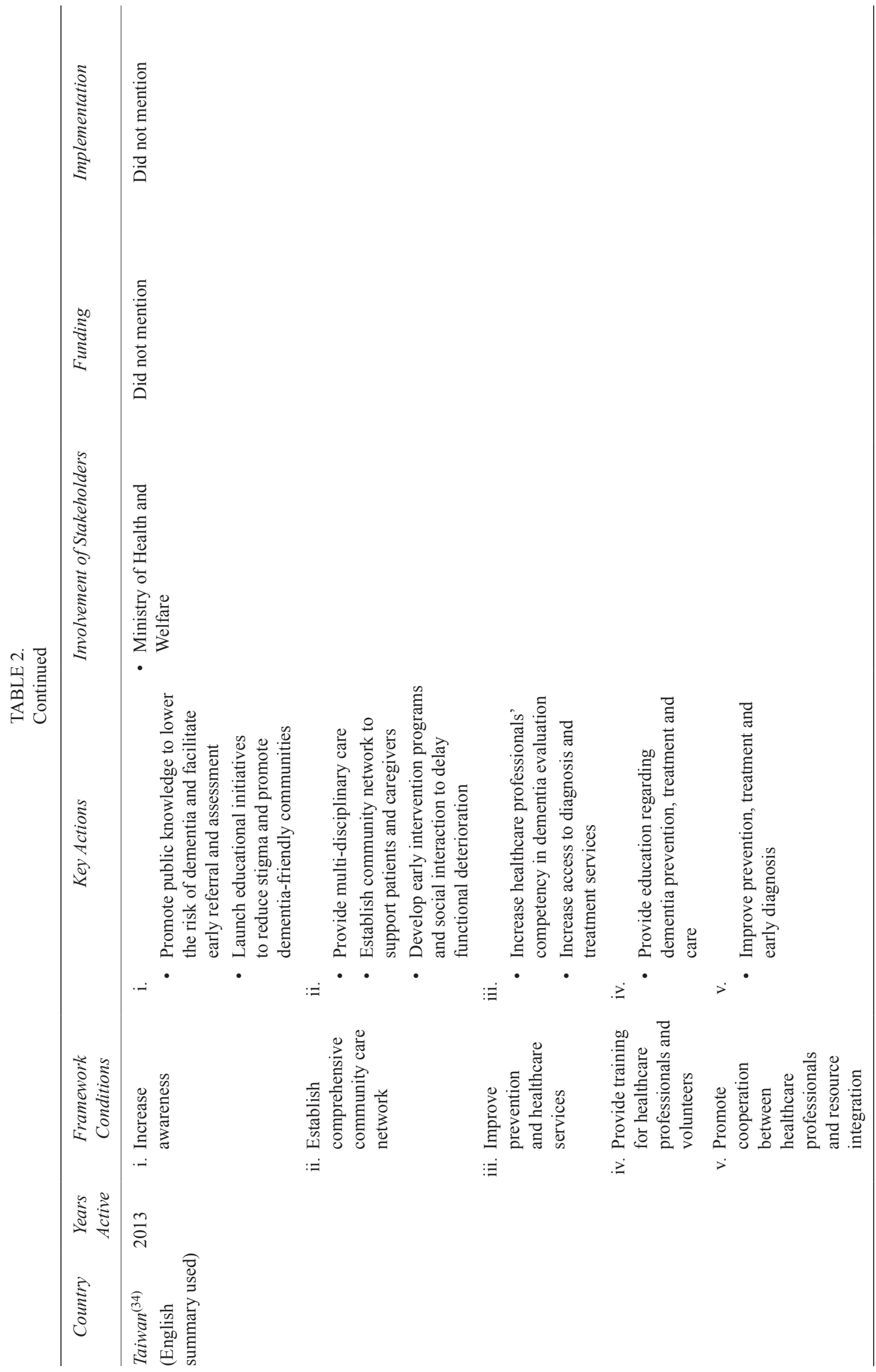


CHOW: NATIONAL DEMENTIA STRATEGIES
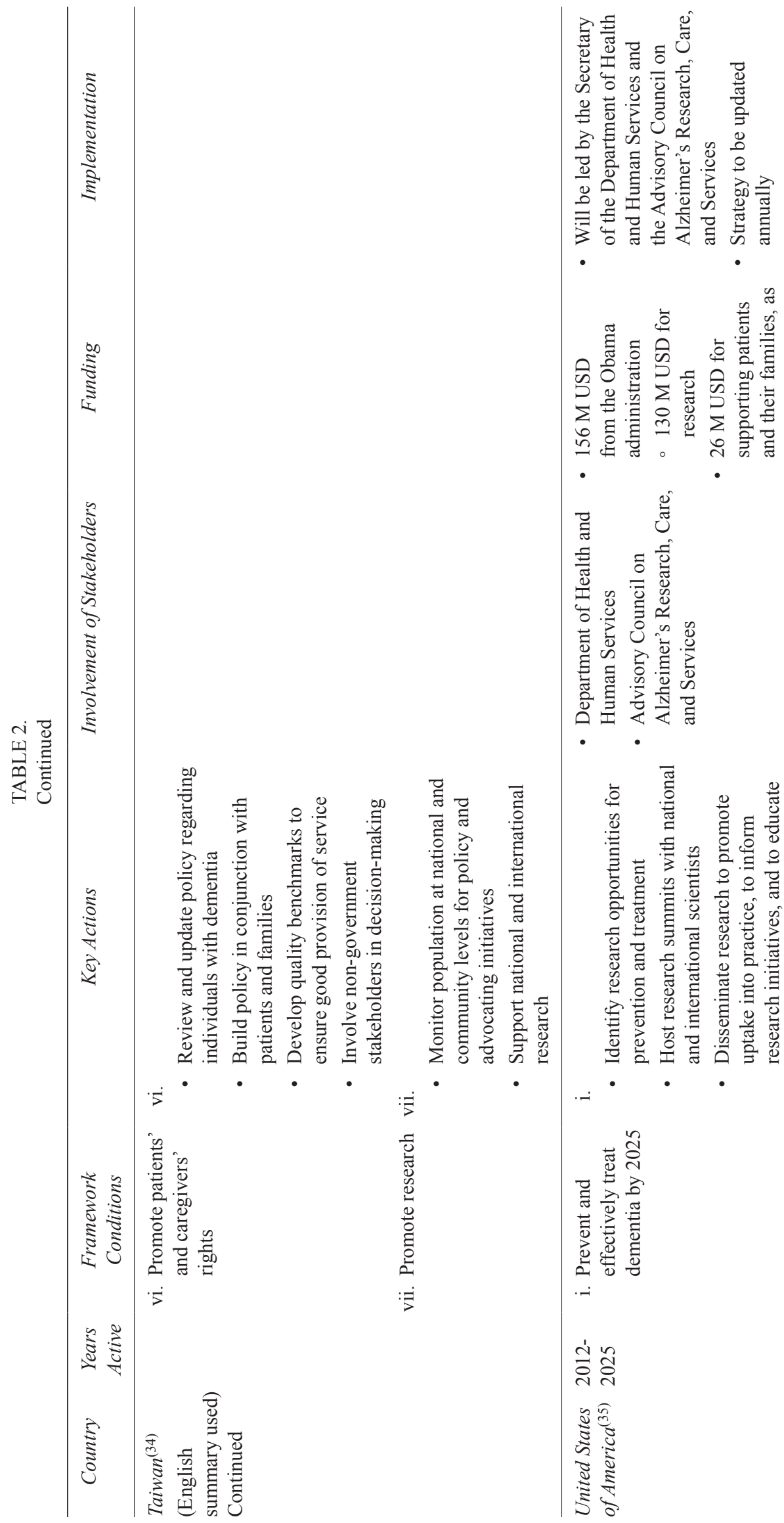

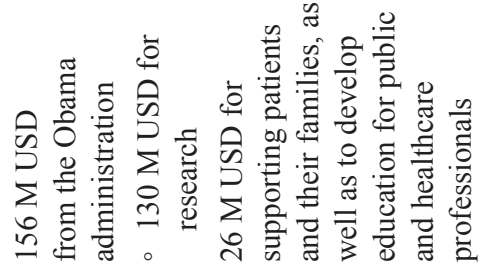

-

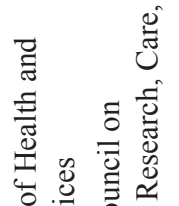

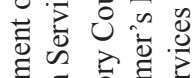

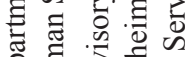

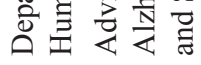
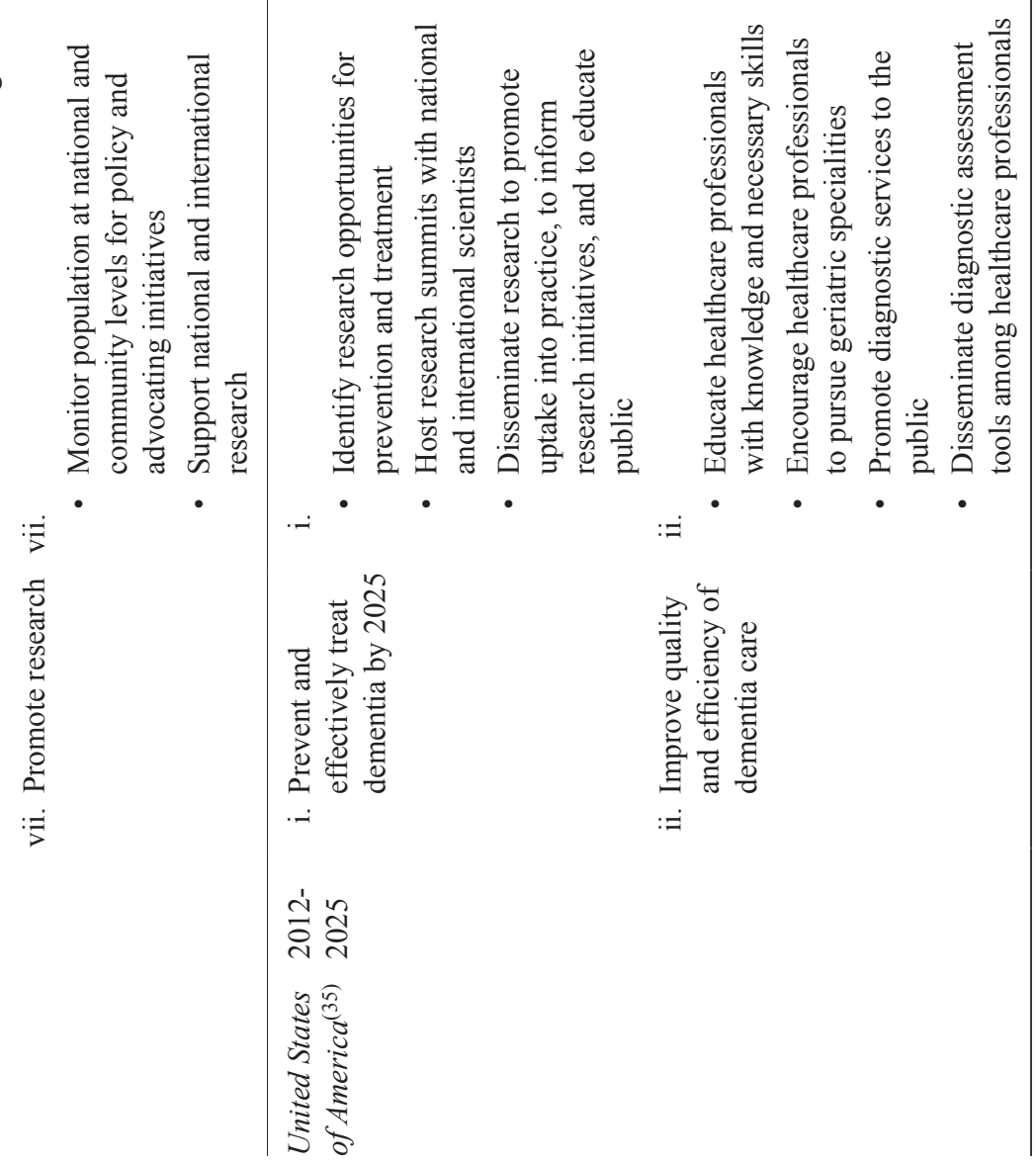
CHOW: NATIONAL DEMENTIA STRATEGIES

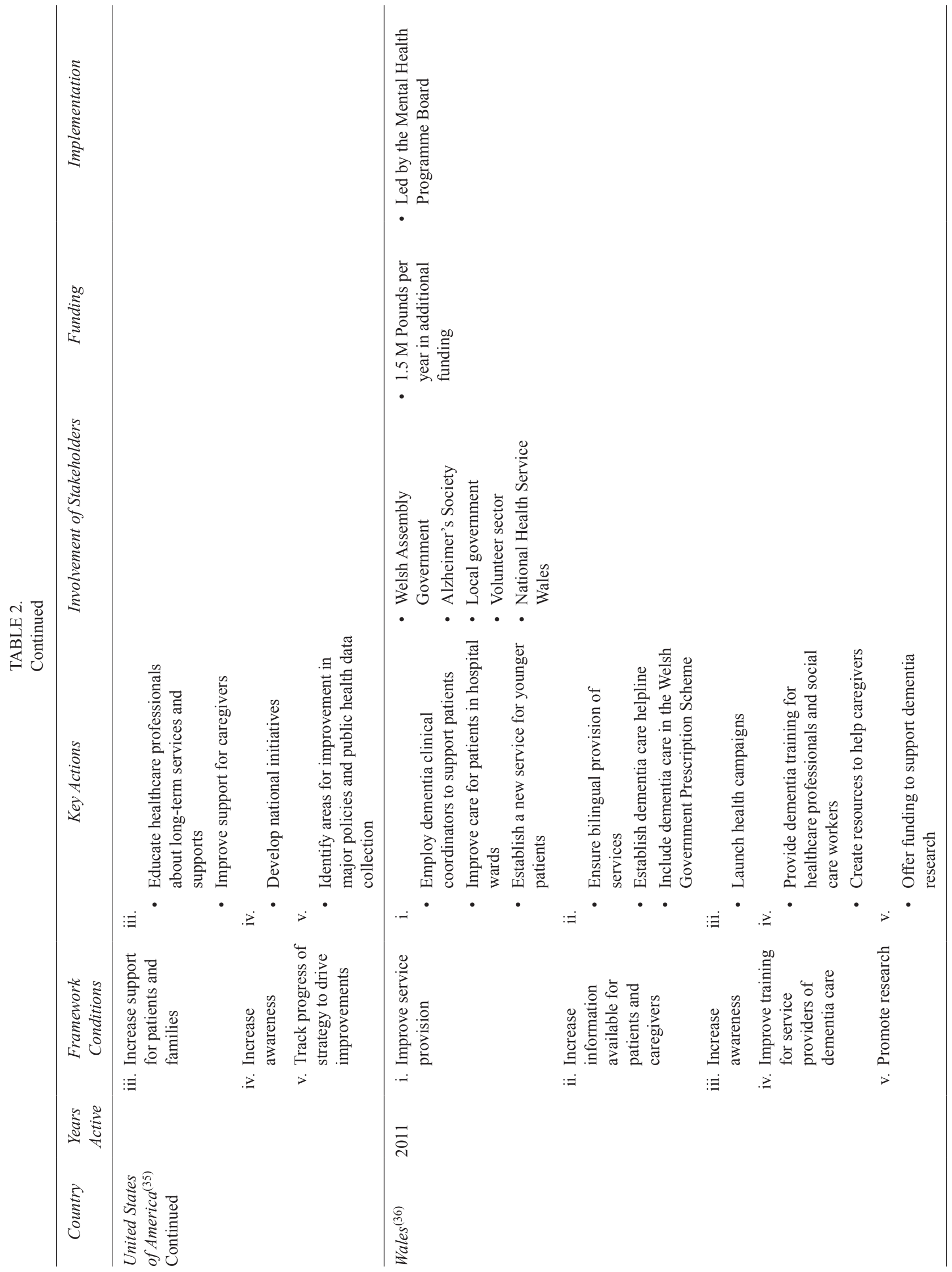




\section{Increase Awareness}

The NDS of 18 countries (Australia, Czech Republic, England, Finland, Greece, Indonesia, Ireland, Israel, Luxembourg, Malta, Mexico, The Netherlands, Northern Ireland, Puerto Rico, Switzerland, Taiwan, USA, Wales) aimed to increase awareness of dementia by providing more education and information to families and the community. Some countries also planned to launch awareness campaigns and create dementiafriendly communities, thereby promoting prevention and allowing for facilitation of early referral and assessment. In particular, Finland and Ireland had unique actions by which they hoped to raise awareness of dementia. Finland developed an online portal with information about memory loss (www. muisti.fi), while Ireland implemented "The National Physical Activity Plan" to promote healthy lifestyles involving regular physical activity.

\section{Reduce Stigma}

Six countries (Cuba, Czech Republic, Ireland, Israel, Italy, Malta) aimed to reduce the stigma surrounding dementia through awareness campaigns. For example, Cuba planned to launch dementia campaigns, television and radio programs, and health-promotion activities, along with establishing annual events for "World Alzheimer's Day" on September 21.

\section{Identify Support Services}

Identifying and establishing support services for patients and caregivers was a common priority among 14 countries (Australia, Cuba, Czech Republic, England, France, Greece, Israel, Japan, Luxembourg, Northern Ireland, Norway, Scotland, USA, Wales). These countries planned to provide psychological support to caregivers by creating support networks and promoting peer support. In addition, France, Israel, and Wales established telephone helplines for caregivers, while France also created a website containing information and advice. The Czech Republic is the only country that also included in its NDS the need to provide financial support to caregivers, by establishing a financial support system for all caregivers, as well as providing support for employed people who are informal caregivers.

In terms of providing support services for patients, countries had varying means of achieving this goal. Several countries appointed a professional to support patients throughout the disease trajectory-England established the new role of a "dementia adviser" to serve as a point of contact for patients and caregivers; France appointed coordinators to facilitate connections between health-care professionals (HCPs) caring for patients; Wales employed "dementia clinical coordinators" to support patients. Japan approached this priority from a different angle by encouraging the public to become involved in supporting individuals with dementia. 5.8 million Japanese volunteers, known as "dementia supporters", had already completed an accredited program to learn how to support patients and families, and the Japanese NDS aimed to increase the number of "dementia supporters" to 8 million people. Japan also established neighbourhood "watch networks" to help patients who wander. Meanwhile, France, Northern Ireland, and Wales all prioritized increasing support for younger adults with dementia, while France and Northern Ireland also focused on patients with behavioural problems and learning disabilities, respectively. Scotland planned to improve support for all newly diagnosed patients by offering a minimum of one-year, post-diagnostic support. Norway hoped to better support people with dementia living at home, and thus proposed an amendment to the Social Services Act to mandate all municipalities to offer day programs to these patients by 2020 . Norway is also the only country that aimed to establish educational programs specifically for patients.

\section{Improve Care}

Improving dementia care is also a notable framework condition listed by all of the countries, although details varied slightly by country. In general, improving the quality of care included promoting multi-disciplinary care for patients, and assessing and increasing the ease of access to services via dementia-friendly communities and guidance resources. The NDSs of Australia, Cuba, Czech Republic, England, Finland, and France wanted to standardize care by implementing clinical guidelines and/or developing explicit care pathways for the management and care of patients. Additionally, Finland planned to provide 24-hour care to patients. Australia and England aimed to improve care in hospitals by establishing dementia-specific health-care teams. Likewise, several countries (England, Ireland, Israel, Japan, Norway) appointed a specialized HCP to lead quality improvement of services and coordinate dementia care for patients. Finally, Australia, Czech Republic, and Norway had unique processes to improve dementia care. Australia aims to improve access to end-of-life and palliative care by promoting advance care planning after diagnosis of dementia. Interestingly, Czech Republic is the only NDS to establish standardized rules for assessing the ability of dementia patients to drive safely. Finally, Norway's priority is to conduct home visits for older adults to promote dementia prevention.

\section{Improve Training and Education for HCPs}

Improving training and education for HCPs was a priority in 16 countries' NDSs (Australia, Cuba, Czech Republic, England, Greece, Indonesia, Ireland, Israel, Italy, Korea, Malta, Mexico, Puerto Rico, Switzerland, USA, Wales). Cuba, Czech Republic, Mexico, Korea, and USA specified an aim to increase the number of dementia specialists by including geriatrics training in undergraduate and graduate curricula for related specialties. In particular, Korea set a goal of increasing the number of HCPs specialized in caring for dementia patients to 6,000 by 2012 . While the aforementioned NDSs 
focused on offering courses for those training to be HCPs, Cuba also aimed to offer refresher courses about dementia for HCPs, while Greece offered clinical and research scholarships. In contrast, Ireland and Israel focused on training general practitioners on the diagnosis and management of dementia care.

\section{Promote Research}

The NDSs of 17 countries (Australia, Cuba, Czech Republic, England, France, Greece, Israel, Japan, Malta, Mexico, The Netherlands, Northern Ireland, Norway, Scotland, Taiwan, USA, Wales) also aimed to promote dementia research, to better identify risk factors and develop diagnostic tools. In addition, Australia and Cuba specified the following topics as areas of interest for dementia research: causes, incidence rates, diagnosis, treatment, and a cure. The United States also included the goal of effectively treating dementia by 2025 . Finally, England and the USA planned to host research summits with national and international scientists involved in dementia research.

\section{Funding for NDS}

Funding for the NDS was specified by 13 of the 25 countries (52\%) (Australia, Czech Republic, Finland, France, Greece, Indonesia, Ireland, Italy, Japan, The Netherlands, Norway, USA, Wales); however, only six (Australia, France, Ireland, The Netherlands, USA, Wales) of these countries disclosed the amount of funding received. The United States received 156 million USD from the Obama administration (prior to 2017) for their NDS, of which 130 million USD is devoted to research and the remaining 26 million USD for supporting patients, families, and HCPs. Australia has specified that they have a 200 million AUD budget provided by the national government for their NDS, which includes 50 million AUD to establish a National Institute for Dementia Research. France has received a total of 1.2 billion Euros of funding from the health insurance system and the National Fund for the Autonomy of Elderly and Disabled People, including 200 million Euros for improving health care and another 200 million Euros for research. Other European countries have supported the NDS to the magnitude of 105,000 Euros for Ireland in the first year of the strategy, 85 million Euros for The Netherlands, and additional funding of 1.5 million Pounds annually for Wales.

\section{Implementation of NDS}

The following 16 countries specified in the NDS how their strategy will be implemented: Cuba, Czech Republic, England, Finland, France, Greece, Indonesia, Ireland, Israel, Malta, Mexico, Norway, Scotland, Switzerland, USA, Wales. Most of the plans for implementation were vague, with the exceptions of Cuba and Finland, which both included very well-structured and detailed plans. In Cuba, the National Di- rectorate of Primary Health Care and the Department of the Elderly, Mental Health, and Social Welfare were responsible for the overall coordination of the key actions outlined in the NDS. Specific key actions of research, training HCPs, and developing public educational messages were further delegated to related organizations listed in Table 2. Likewise, a number of governmental agencies and non-governmental organizations in Finland were assigned relevant responsibilities for implementing the NDS. In addition, France committed to monitor and report the progress of its NDS every six months, while Cuba, Czech Republic, England, and the USA tracked their progress on an annual basis.

\section{DISCUSSION}

This review comprehensively lists the components of 25 of the 29 countries with a NDS, and reports the overarching themes that present across all strategies. To our knowledge, this is the first review to summarize and synthesize all of these NDSs in a single report. The results within, especially the similarities between the strategies, may be of great interest to policy-makers, HCPs, and other key stakeholders involved with Canada's forthcoming NDS.

Most NDSs had five major framework conditions: increasing awareness of dementia, identifying support services, improving the quality of dementia care, as well as improving training and education and promoting research. While not a component of the majority of NDSs, another common theme was reducing stigma. Some countries explicitly described the actions they will take to accomplish these objectives (i.e., England), while others list vague actions (i.e., Indonesia). Unfortunately, only a few countries have had follow-up studies evaluating the effectiveness of their NDS, while discussing ways to improve the strategy. ${ }^{(40-42)}$ When establishing Canada's NDS, we would recommend investigating the efficacy of the NDSs of other countries further, and looking into which of, and under what circumstances, the aforementioned major framework conditions are effective. However, successes in other countries may or may not apply in Canada, given differences in health-care systems. In particular, because health care in Canada is primarily a provincial and territorial responsibility, Canada's NDS will require extraordinary cooperation across governments.

Notably, all G7 countries have disclosed that they have dedicated tremendous financial resources towards their NDSs, ranging from 156 million USD by the United States of America to 1.2 billion Euros by France. It would be interesting to study the effectiveness of these NDSs to determine if there is a positive correlation between financial resources and efficacy. It is, however, important to note that France offers a universal health-care system, while the United States does not. Hence, the French government likely needs to take on a greater financial burden. Nevertheless, Canada should be prepared to dedicate significant resources towards an NDS, as a country that also has a universal health-care system. 
Some might argue that since health care is a provincial responsibility, each Canadian province should have their own local strategies, and indeed all ten provinces have already developed, or are currently developing, their own dementia strategies-British Columbia, ${ }^{(43)}$ Newfoundland and Labrador, ${ }^{(44)}$ Nova Scotia, ${ }^{(45)}$ Manitoba, ${ }^{(46)}$ Prince Edward Island, ${ }^{(47)}$ New Brunswick, ${ }^{(48)}$ Quebec, ${ }^{(49)}$ Alberta, ${ }^{(50)}$ Saskatchewan, ${ }^{(51)}$ and most recently Ontario. ${ }^{(52)}$ Unfortunately, the delivery of health-care services to dementia patients and their caregivers is only one component of a comprehensive dementia strategy, and many other components including education, awareness, and de-stigmatization would clearly benefit from a national approach in contrast to a local patchwork of strategies. Canada, in particular, must also pay special attention to dementia in Indigenous communities, a problem which crosses provincial boundaries, and which has been a remarkably understudied area of research. ${ }^{(53)}$

Another key lesson to be learned from a review of these NDSs is the process of NDS development and, in particular, the identification of key stakeholders. These include all appropriate federal government ministries (e.g., Health; Employment, Workforce Development, and Labour; Finance; Canadian Heritage; Indigenous Services), provincial representatives, Canadian Institute of Health Research, Alzheimer's Society of Canada, Canadian Medical Association, specialist physician groups (Neurology, Psychiatry, Geriatric Psychiatry, Geriatric Medicine, Palliative Care), Canadian Nurses Association, and individual patients and caregivers, where appropriate. This list is far from complete and consideration should also be given to the inclusion of other potentially valuable contributors, including, for example, pharmacists, home care service providers, occupational therapists, physiotherapists, insurance agency representatives, and pension plan mangers. We strongly support the inclusion of specific milestones and a pre-determined evaluation process. A Canadian NDS can take advantage of established organizations to provide research into the strategy's effectiveness, including the Canadian Institute for Health Information, the Institute for Clinical Evaluative Sciences, and the Canadian Consortium on Neurodegeneration in Aging.

In 2016, the Canadian government authorized the Standing Senate Committee on Social Affairs, Science and Technology to assess and report on the current issue of dementia in Canada. Within the report, the need for a National Dementia Strategy was emphasized. As noted by the Alzheimer Society of Canada, "...we are far behind other countries in our approach to [the issue of dementia], being one of only two G7 countries (along with Germany) that do not have a comprehensive national dementia strategy". The Senate Standing Committee, therefore, made 29 recommendations for a National Dementia Strategy, as summarized in Table $3{ }^{(54)}$ Reassuringly, many of the initiatives and themes discussed above, including important process issues (e.g., appropriate stakeholder involvement, specified funding) and priorities (e.g., public awareness), were mentioned in this document, though many specific details were lacking.
As noted in the Introduction, it is not clear why it has taken Canada so long to develop a NDS. As with all public policy development, there are always competing interests and other political considerations, especially when considerable financial resources are involved. We have already discussed the provincial/territorial jurisdictional issues. Finally, it is possible that ageism and stigma have also played a role in Canada's delayed response.

A limitation of this review is that some of the listed 29 countries did not have an easily accessible document that could be translated into English for inclusion in this review. For the NDSs included in our review that were translated from a foreign language, the unofficial English translations used may not accurately represent the original NDS.

\section{CONCLUSION}

Our review was able to comprehensively list and compare 25 of the 29 countries with National Dementia Strategies. The results suggest five major priorities that are covered by most NDSs: increasing awareness, establishing support services, improving standard of care, improving training and education for HCPs, and promoting research. We hope that policy-makers in Canada will review these NDSs, learn from their examples, and develop an effective NDS for our country.

\section{ACKNOWLEDGEMENTS}

Dr. Nathan Herrmann is funded in part by the Canadian Consortium on Neurodegeneration in Aging, supported by the Canadian Institute of Health Research and its partners.

\section{CONFLICT OF INTEREST DISCLOSURES}

Unrelated to the current study, Dr. Herrmann has received research funding from Lundbeck, Roche and Axovant and consultation fees from Merck, Lilly, Astellas and Mediti. The authors declare that no conflicts of interest exist.

\section{REFERENCES}

1. Alzheimer's Disease International. Dementia statistics [Internet]. London, UK: Alzheimer's Disease International. 2017. Accessed 2017 Jul 12. Available from: https:/www.alz.co.uk/ research/statistics

2. Bhattacharya D, Bhatt J. Seven Foundational Principles of Population Health Policy. Pop Health Manage. 2017;20(5):383-88.

3. Alzheimer's Disease International. Dementia plans [Internet]. London, UK: Alzheimer's Disease International; 2017. Accessed 2017 Jul 31. Available from: https:/www.alz.co.uk/dementia-plans

4. Alzheimer Society of Canada. Canada's national dementia strategy [Internet]. Toronto, ON: Alzheimer Society of Canada; 2017. Accessed 2017 Jul 31. Available from: http://www. alzheimer.ca/en/Get-involved/Advocacy/National-dementiastrategy 
TABLE 3.

The Standing Senate Committee's recommendations for Canada's national dementia strategy ${ }^{\mathrm{a}}$

\begin{tabular}{|c|c|}
\hline Recommendation & Action Item \\
\hline 1 & $\begin{array}{l}\text { - Establish the Canadian Partnership to Address Dementia } \\
\text { - Include a mandate to create and implement a National Dementia Strategy }\end{array}$ \\
\hline 2 & $\begin{array}{l}\text { - Model the Canadian Partnership to Address Dementia after the approach taken in the Canadian Partnership Against Cancer } \\
\text { Include the following stakeholders in the new dementia partnership } \\
\text { O Federal, provincial, and territorial governments } \\
\text { Dementia and other health-related organizations } \\
\text { O Individuals with dementia } \\
\text { O Caregivers } \\
\circ \text { Healthcare professionals } \\
\text { Housing organizations } \\
\text { Researchers } \\
\text { - Indigenous community } \\
\text { Evaluate, report on, and update the National Dementia Strategy annually } \\
\text { Federal government funding of at least } \$ 30 \mathrm{M} \text { annually for the Canadian Partnership to Address Dementia }\end{array}$ \\
\hline 3 & $\begin{array}{l}\text { - Adjust the annual government funding provided to the Canadian Partnership to Address Dementia according to annual } \\
\text { evaluations and strategy updates }\end{array}$ \\
\hline 4 & $\begin{array}{l}\text { - Use the following documents when creating the National Dementia Strategy: } \\
\text { o The Canadian Alzheimer's Disease and Dementia Partnership: Strategic Objectives (Alzheimer Society of Canada) } \\
\text { - Improving Dementia Care Worldwide: Ideas and Advice on Developing and Implementing a National Dementia Plan } \\
\text { (Alzheimer's Disease International) }\end{array}$ \\
\hline 5 & $\begin{array}{l}\text { - Federal government funding of approximately } \$ 100 \mathrm{M} \text { annually for the Canadian Institutes of Health Research's De- } \\
\text { mentia Research Strategy }\end{array}$ \\
\hline 6 & $\begin{array}{l}\text { Develop a public awareness campaign that promotes the following items } \\
\circ \text { Dementia Friends Canada website } \\
\circ \text { Prevention } \\
\circ \text { Early diagnosis } \\
\circ \text { Symptom recognition } \\
\circ \text { Quality of life } \\
\circ \text { Services } \\
\circ \text { Supports }\end{array}$ \\
\hline 7 & - Develop public awareness campaigns on healthy eating and active lifestyles \\
\hline 8 & $\begin{array}{l}\text { - Adequate federal government funding for the Canadian Chronic Disease Surveillance Program } \\
\text { - Aim to provide robust, timely and accessible dementia surveillance data beginning in } 2017\end{array}$ \\
\hline 9 & - Encourage the implementation of the Alzheimer Society of Canada's First Link ${ }^{\circledR}$ early intervention program \\
\hline 10 & $\begin{array}{l}\text { - Federal government should explore fiscal options to alleviate the financial burden on informal caregivers } \\
\text { Possible options: } \\
\text { o Expand the Employment Insurance compassionate care benefit beyond palliative care } \\
\text { - Amend the Caregiver Tax Credit and the Family Caregiver Tax Credit to make them refundable }\end{array}$ \\
\hline 11 & - Promote workplace best practices to support employees who are caregivers \\
\hline 12 & $\begin{array}{l}\text { Provide the following additional supports for caregivers } \\
\circ \text { Education and training } \\
\circ \text { Respite services } \\
\circ \text { Online portal with information about dementia programs and initiatives }\end{array}$ \\
\hline 13 & - Federal government funding of $\$ 3 \mathrm{~B}$ over 4 years for a comprehensive package of home care services \\
\hline 14 & $\begin{array}{l}\text { - Routinely evaluate and report on the use of government funding for home care services } \\
\text { - Provide annual, success-based adjustments to funding }\end{array}$ \\
\hline 15 & - Assess the need for home care funding beyond the initial 4-year period \\
\hline
\end{tabular}


TABLE 3.

Continued

\begin{tabular}{|c|c|}
\hline Recommendation & Action Item \\
\hline 16 & - Promote innovative technologies and the Home-Care-Plus model (integrates specialists in dementia care into home care) \\
\hline 17 & $\begin{array}{l}\text { - Assess the fiscal barriers preventing the integration of health and social services } \\
\text { - Implement the changes needed to successfully integrate health and social services }\end{array}$ \\
\hline 18 & $\begin{array}{l}\text { - Establish targets for implementing electronic health and prescription drug systems } \\
\text { - Promote the use of electronic databases by healthcare professionals } \\
\text { - Report on the progress of implementing these electronic systems }\end{array}$ \\
\hline 19 & $\begin{array}{l}\text { - Promote models of dementia care that integrate healthcare delivery (e.g. Dementia-plus Care Model) } \\
\text { - Integrate social services into dementia care } \\
\text { - Promote advance care planning for palliative and end-of-life care }\end{array}$ \\
\hline 20 & - Federal government funding of $\$ 450 \mathrm{M}$ to develop more continuing care infrastructure \\
\hline 21 & $\begin{array}{l}\text { - Examine and update as necessary the staffing, care, and accommodation standards in seniors' residences } \\
\text { - Improve access to seniors' housing }\end{array}$ \\
\hline 22 & - Assess and promote models of dementia care for rural and remote communities \\
\hline 23 & - Expedite federal government funding for rural and remote communities \\
\hline 24 & - Support the Home and Community Care Program by Health Canada's First Nations and Inuit Health Branch \\
\hline 25 & - Develop standards of care for acute-care hospitals \\
\hline 26 & - Provide dementia care training and professional development for healthcare professionals \\
\hline 27 & - Develop a Best Practices Portal for providers of dementia care \\
\hline 28 & - Consider the programs and practices listed in the report for inclusion in the Best Practices Portal \\
\hline 29 & - Include individuals with dementia in all aspects of the Canadian Partnership to Address Dementia \\
\hline
\end{tabular}

adapted from Reference \#54.

5. G7 Information Centre. Health Ministerials. G8 Dementia Summit Declaration. Toronto, ON: University of Toronto; 2013. Available from: http://www.g8.utoronto.ca/healthG8/2013dementia-declaration.html

6. Vogel, L. Canada releases national dementia plan. CMAJ. 2014;186(15):E562.

7. Australian Health Ministers Advisory Council. National framework for action on dementia 2015-2019. Canberra, Australia: Department of Health; 2015.

8. Ministry of Public Health, Cuba. Cuban strategy for Alzheimer's disease and dementia syndromes. Havana, Cuba: Ministry of Public Health; 2013.

9. Ministry of Health, Czech Republic. The national action plan for Alzheimer's disease and other similar diseases for 2016-2019. Prague, Czech Republic: Ministry of Health; 2015.

10. Department of Health, United Kingdom. Living well with dementia: a national dementia strategy. London, UK: Department of Health; 2009.

11. Finnish Ministry of Social Affairs and Health. National memory programme 2012-2020: creating a "memory-friendly" Finland. Helsinki, Finland: Ministry of Social Affairs and Health; 2013.
12. National plan for Alzheimer's and related diseases 2008-2012. France; 2008. Available from: https://www.alz.co.uk/sites/ default/files/plans/Alzheimer-Plan-2008-2012-France-ENG. pdf

13. Ministry of Health, Greece. National action plan for dementia-Alzheimer's disease. Athens, Greece: Ministry of Health; 2016.

14. Ministry of Health, Indonesia. National strategy for the management of Alzheimer's and other dementia diseases: towards healthy and productive older persons. Jakarta, Indonesia: Ministry of Health; 2015.

15. Department of Health, Ireland. The Irish national dementia strategy. Dublin, Ireland: Department of Health; 2014.

16. Ministry of Health, State of Israel. The national program for addressing Alzheimer's disease and other types of dementia [Internet]. Jerusalem, State of Israel: Ministry of Health; n.d. Accessed 2017 Aug 25. Available from: https:/www.health. gov.il/English/Topics/SeniorHealth/DEMENTIA/Pages/ National_program.aspx

17. Di Fiandra T, Canevelli M, Di Pucchio A, et al. The Italian dementia national plan. Ann Ist Super Sanità. 2015;51(4):261-64. 
18. Di Fiandra T. The new Italian national strategy. Rome, Italy: Ministry of Health; 2014. Available from: https://www.alz. co.uk/sites/default/files/plans/italy.pdf

19. Lanzetta MC, Naddeos A. Conference unified. Rome, Italy; 2014. Available from: https:/www.alz.co.uk/sites/default/files/ plans/italy-english.pdf

20. Health, Labor \& Welfare Ministry, Japan. New orange plan on dementia care. Tokyo, Japan: The Ministry; 2015.

21. New dementia strategy to cope with projected rise in cases. The Japan Times [Internet]. 2015 Jan 27. Accessed 2017 Aug 23. Available from: https:/www.japantimes.co.jp/news/2015/01/27/ national/science-health/new-dementia-strategy-to-cope-withprojected-rise-in-cases/\#.WZ2h71yvxSY.

22. Hayashi M. Dementia: Japan's experience. Presentation made at the Dementia Awareness Week Conference, 2015 Jun 1, Glasgow, Scotland. Available from: http://daw.dementiascotland.org/wpcontent/uploads/2015/06/Mayumi-Hayashi-Japans-Policy.pdf

23. Lee S. Korea's "War on Dementia". Presented at The Changing Face of Dementia, the 26th International Conference of Alzheimer's Disease International, 2011 Mar 26-29, Toronto, Canada. Available from: https://www.alz.co.uk/sites/default/ files/plans/Korea-war-on-dementia.pdf

24. Lee S. Dementia strategy Korea. Int J Geriatr Psychiatry. 2010;25(9):931-32.

25. Council of Government, Luxembourg. Luxembourg national dementia plan. Luxembourg City, Grand Duchy of Luxembourg; 2013.

26. Parliamentary Secretariat for Rights of Persons with Disability and Active Ageing, Malta. Empowering change: a national strategy on dementia 2015-2023. Valetta, Malta: Government of Malta; 2015.

27. National Institute of Geriatrics, Ministry of Health, Mexico. Action plan: Alzheimer's and other dementias. Mexico City, Mexico; 2014.

28. Deltaplan dementia [website]. Amersfoort, The Netherlands: Deltaplan Dementia; 2017. Available from: https://deltaplan dementie.nl/en

29. Norwegian Ministry of Health and Care Services. Dementia plan 2020. Oslo, Norway: The Ministry; 2016.

30. Department of Health, Social Services, and Public Safety, Northern Ireland. Improving dementia services in Northern Ireland. Belfast, Northern Ireland: The Department; 2011.

31. Department of Health, Puerto Rico. Alzheimer's disease action plan for Puerto Rico 2015-2025. San Juan, Puerto Rico; n.d.

32. Government of Scotland. Scotland's national dementia strategy 2017-2020. Edinborough, Scotland; 2017.

33. Federal Office of Public Health, Swiss Conference of the Cantonal Ministers of Public Health. National dementia strategy 2014 2017. Bern, Switzerland: Federal Office of Public Health; 2017.

34. Ministry of Health and Welfare, Taiwan. Taiwan dementia policy: a framework for prevention and care. Taipei, Taiwan: The Ministry; 2014.

35. Assistant Secretary for Planning and Evaluation, U.S. Department of Health and Human Services. National plan to address Alzheimer's disease. Washington, DC: The Department; 2012.
36. Welsh Assembly Government. National dementia vision for Wales. Cardiff, Wales: Government of Wales; 2011.

37. PAMI. Plan estratégico nacional pami para un cerebro saludable, enfermedad de Alzheimer y otras demencias 2016-2019. Buenos Aires, Argentina: PAMI; 2015.

38. Conapam. Plan nacional para la enfermedad de Alzheimer y demencias relacionadas esfuerzos compartidos 2014-2024. San José, Costa Rica: Conapam; 2014.

39. Ministrstvo za Zdravje, Slovenia. Strategija obvladovanja demence v sloveniji do leta 2020. Ljubljana, Republic of Slovenia: The Ministry; 2016.

40. Department of Health, United Kingdom. Equality impact assessment for the national dementia strategy. London, UK: The Department; 2009.

41. Palethorpe AJ. Impact assessment of national dementia strategy. London, UK: Department of Health; 2009.

42. National Institute for Health and Welfare, Finland. Human impact assessment [Internet]. Helsinki, Finland: Ministry of Social Affairs and Health; 2015. Accessed cited 2017 Aug 25. Available from: https://www.thl.fi/en/web/health-promotion/ human-impact-assessment

43. Ministry of Health, British Columbia. The provincial dementia action plan for British Columbia. Priorities and Actions for Health System and Service Redesign. Vancouver, BC: The Ministry; 2012.

44. Department of Health \& Community Services, Newfoundland and Labrador. Provincial strategy on Alzheimer disease and other dementias. A plan of action. St. John's, Newfoundland: The Department; 2001.

45. Department of Health and Wellness, Nova Scotia. Towards understanding: a dementia strategy for Nova Scotia. Halifax, NS: The Department; 2015.

46. Manitoba Health. Manitoba's framework for Alzheimer's disease and other dementias. Winnipeg, MB; n.d.

47. Alzheimer Society of Prince Edward Island. Provincial dementia strategy [Internet]. Charlottetown, PEI: Alzheimer Society of Canada \& PEI; 2016. Accessed cited 2017 Sept 3. Available from: http://www.alzheimer.ca/en/pei/Get-involved/ Raise-your-voice/Provincial-Dementia-Strategy

48. Keefe J. New Brunswick government says aging strategy plans coming soon. Global News [Internet], 2017 May 3. Accessed 2017 Sept 3. Available from: http://globalnews. ca/news/3424615/new-brunswick-government-says-agingstrategy-plans-coming-soon/

49. Bergman $H$. The Quebec Alzheimer plan: the never-ending cycle from practice to research to policy and back. Seminar presented by Dept. of Family Medicine at McGill University, 2013 Jan 14, Montreal, Canada. Poster and background information available from: https://www.mcgill.ca/familymed/files/familymed/ rd_seminar_bergman_2013-01-14.pdf

50. Graney E. Alberta dementia strategy coming soon, health minister promises. Edmonton Sun [Internet], 2017 Jun 5. Accessed 2017 Sept 3. Available from: http://www.edmontonsun. com/2017/06/05/alberta-dementia-strategy-coming-soonhealth-minister-promises 
51. Provincial Advisory Committee of Older Persons. A strategy for Alzheimer disease and related dementias in Saskatchewan. Regina, SK: The Committee; 2004.

52. Alzheimer Society of Ontario. Ontario achieves a fully funded dementia strategy [news release][Internet]. Toronto, ON: Alzheimer Society of Canada; 2017. Accessed cited 2017 Sept 3. Available from: http://www.alzheimer.ca/en/on/Get-involved/ Advocacy/Ontario/Ontario-dementia-strategy

53. Jacklin KM, Walker JD, Shawande M. The emergence of dementia as a health concern among First Nations populations in Alberta, Canada. Can J Public Health. 2013;104(1):e39-e44.
54. Standing Senate Committee on Social Affairs, Science and Technology. Dementia in Canada: a national strategy for dementia-friendly communities. Ottawa, ON: The Committee; 2016. Available from: http://alzheimer.ca/sites/default/files/ Files/national/Advocacy/SOCI_6thReport_DementiaInCanadaWEB_e.pdf

Correspondence to: Dr. Nathan Herrmann, MD, Division of Geriatric Psychiatry, Sunnybrook Health Sciences Centre, 2075 Bayview Ave., Rm. FG19, Toronto, ON, Canada M4N 3M5 E-mail: nathan.herrmann@sunnybrook.ca 